\title{
Motivos de Xenia en los mosaicos romanos de Hispania
}

\author{
Representations of Xenia on the Roman Mosaics \\ of Hispania
}

\author{
María Pilar San Nicolás Pedraz*
}

\begin{abstract}
RESUMEN
Análisis de los mosaicos hispanos con representaciones de Xenia cuyo origen procede de las pinturas helenísticas. Son imágenes muy características de los productos de la tierra y del mar que el dominus ofrecía a sus invitados (frutas, verduras, legumbres, animales...). Los artistas hispanos las presentan aisladas o en composición geométrica, vegetal o libre como son usuales en el Norte de

Africa. En cuanto a sus contextos arqueológicos corresponden tanto a ambientes de domus como a villae rurales, y se encuentran decorando estancias de prestigio (triclinium, oecus...). La cronología de estos mosaicos abarca desde el siglo i hasta finales del siglo IV o comienzos del $\mathrm{V}$.
\end{abstract}

PALABRAS CLAVE: Xenia, Mosaicos, Productos de la tierra, Productos del mar, Domus, Villae.

\begin{abstract}
Analysis of the Hispanic mosaics with the depictions of Xenia whose origin comes from the Hellenistic paintings. They are very characteristic images of the products of the earth and of the sea that the dominus offered to its companies (fruits, vegetables, vegetables, animals...). The Hispanic artists present them isolated or in geometric composition, vegetable or liberate as they are usual in the North of Africa. As for their archaeological contexts they correspond so much to domus atmospheres as to rural villae, and they are decorating stays of prestige (triclinium, oecus...). The chronology of these mosaics spans from the first to the fourth century B.C. or beginnings of the $V$.
\end{abstract}

KEYWORDS:

Xenia, Mosaics, Products of the earth, Products of the sea, Domus, Villae.

El género de xenia (Varron II 1,2; Vitrubio VI 7,4; Filostrato el Viejo, Imágenes I 31 y || 26) tiene su origen en las pinturas helenísticas y tuvo un gran desarrollo en

* Este trabajo se ha realizado dentro del Proyecto de Investigación HUM 2004- 01056.

UNED. Senda del Rey 7, 28040 Madrid. E-mail: psan@ seo.uned.es 
la musivaria romana de Pompeya y Herculano ${ }^{1}$, pasando a partir del siglo I a Roma y a las provincias del Imperio². En Hispania existe un conjunto, aunque no muy numeroso, un total de 44 ejemplares, sí bastante representativo. Las imágenes son muy características como la fruta (granada, manzana, pera, uva, ciruela, higo...), verdura (alcachofa...), diversos animales (peces, aves...), legumbre, huevos... en suma los productos de la tierra y del mar que el dominus ofrecía a sus invitados $^{3}$.

De los ejemplares conocidos en contexto arqueológico corresponden tanto a ambientes de domus urbanas como a villae rurales, siendo en estas últimas mayoritarias, apreciándose, cuando se pueden determinar, que pavimentaban estancias de prestigio como el triclinium (Vega Baja de Toledo y Torre de Palma, Portugal), oecus (El Ramalete, Navarra) o la antesala del mismo (Carranque, Toledo), peristilo (Marbella, Málaga) o pasillo de este (El Romeral, Lérida), una habitación absidiada (Comunión de Ávila), octogonal (Arróniz, Navarra) o de tipo cultual (Pisoes, Beja, Portugal), así como en áreas residenciales de la ciudad como ocurre con un pavimento de la antigua Colonia Patricia Corduba (Avenida de la Victoria), Emerita Augusta (Casa del Anfiteatro)....

La cronología de estas representaciones hispanas abarca desde el siglo I hasta finales del Iv o comienzos del v.

El repertorio no constituye un conjunto unitario y existe una relevante expansión geográfica. Se distinguen dentro de las composiciones dos formas diferentes, en los emblemata como tema principal o como elemento secundario del cuadro, existiendo varios esquemas diferentes: en guirnaldas de laurel, en guirnaldas de follaje, encerrados en distintos espacios geométricos, en composición libre, como cestos de frutos estacionales, asociados a los meses del año o relacionados con una divinidad, división en la que nos vamos a basar para conformar el trabajo.

1 E. Pernice, Die hellenische Kunst in Pompeji, VI, Pavimente und figürliche Mosaiken, Berlin 1938, pp. 161-164, lám. 62-63; A. Palombi, La fauna marina nei musaici e nei dipinti pompeiani. Pompeiana, Nápoles 1950, pp. 425-455; S. Sgatti, “Caratteri della « natura morta » pompeiana. L” iterpretazione dello sapazio», $A C$ IX,2, 1957, pp. 174-192; L. Foucher, «Influence de la peinture hellénistique sur la mosaïque africaine aux Ile et III siècles», Cahiers de la Tunisie 26-27, 1959, pp. 272-273; J. Caro, «Duex « generi » nella pittura pompeiana: la natura morta e la pittura di giardino», en La pittura di Pompei, 19991; A. Andreae, Antike Bildmosaiken, Mainz 2003; M. Borgongino, Archeobotanica. Reperti vegetali rivenuti nelle città e nel territorio vesuviano, Studi della Sopritendenza Archeologica di Pompei, 16, Roma 2006.

2 J.M. Croisille, Les natures mortes campaniennes: Répertoires, Bruselas 1965; A. de Franciscis «La villa romana di Oplonti», en Neue Forschungen in Pompeji, 1975, pp. 9-38; S. Gozlan, «Logique et fantasie dans les mosaïques de jonchées», Antiquités Africains 14, 1979, pp. 169-187; S. Gozlan, «A propos de quelques pavements africains: les xenia et l'iconographie dionysiaque", en Mosaïque romaine tardive, Paris 1981, pp. 73-87; C. Balmelle et alii, Xenia, Recherche Franco-Tunisiennes sur la mosaïque de l'Afrique antique, Roma 1990; J.P. Darmon et alii, Trames géométriques végétalisees. Collection de l'école française de Rome 288. Roma 2001.

3 P. Veyne, «Les cadeaux des colons à leurs propriétaire la IXe Bucolique et le mausolée d'Isel», RA, 1981, pp. 245-242. 


\section{XENIA EN GUIRNALDAS DE LAUREL}

Figuran de cuatro formas, en la orla del pavimento, en el medallón central, como orla cuadrada del emblema y decorando una figura geométrica:

El primer tipo, en la orla del pavimento, se documenta en un mosaico de Córdoba que se localizó en la Plaza de la Corredera, fechado en el siglos $11-1 \mathrm{II}^{4}$, con alcachofas, cidras y otros frutos no identificables.

Al segundo tipo, en la orla del medallón central, pertenecen cinco mosaicos hispanos: pavimento de esquema a compás de la villa de Pisões (Beja, Portugal), del siglo III, hallado en la habitación 9 considerada de tipo cultual ${ }^{5}$, con cítricos en la guirnalda y estaciones a modo de xenia en las lunetas: aves dentro de un círculo, aves enfrentadas a un cántaro, aves picoteando un racimo de uvas, un cesto de flores (Fig. 1). Mosaico del triclinium de la villa de la Vega Baja de Toledo, de prin-

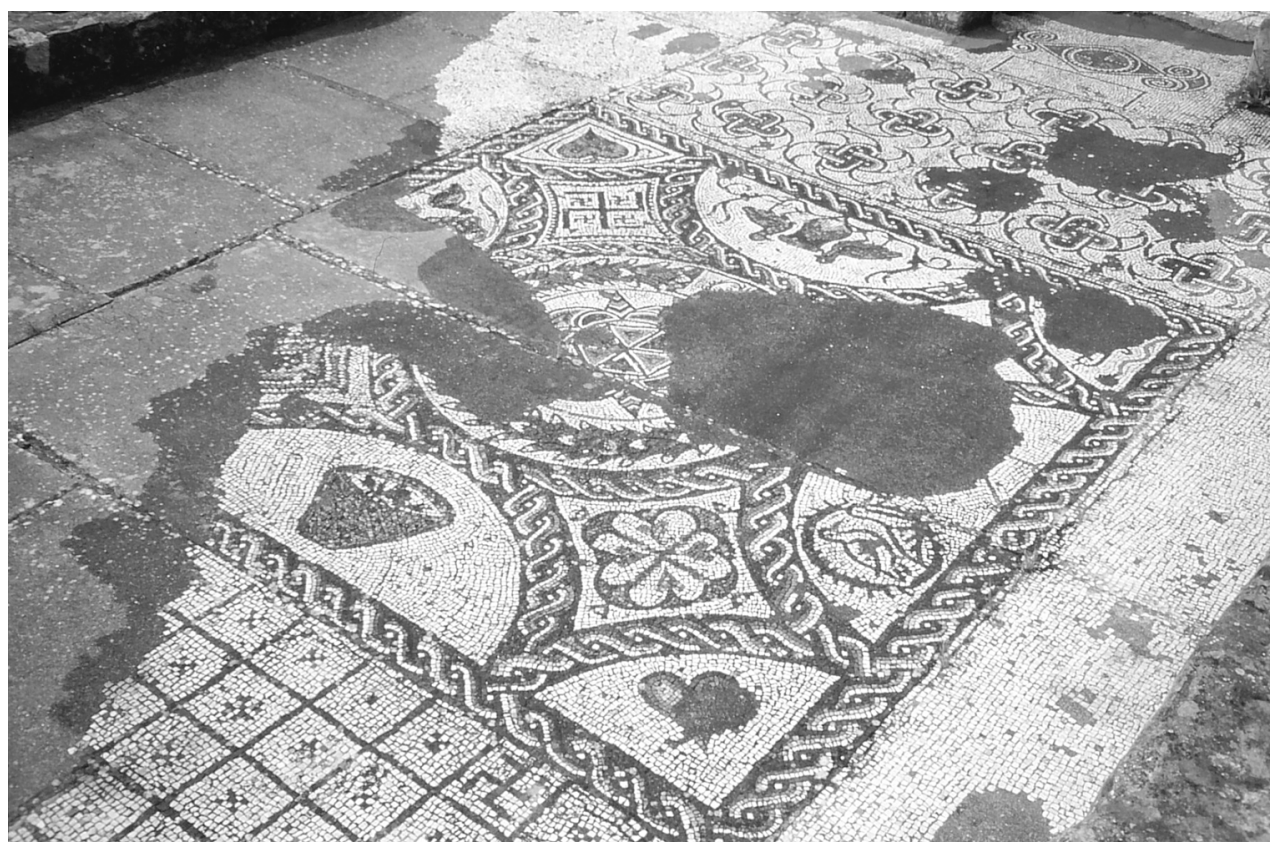

Fig. 1. Mosaico de la villa de Pisoes, Beja, Portugal. Siglo III.

4 J.M. Blázquez, Mosaicos romanos de Córdoba, Jaén y Málaga, CMRE III, Madrid 1981, p. 18, n. ${ }^{\circ}$ 2, fig. 1, lám. $82 \mathrm{~A}$.

${ }^{5}$ M.L. Costa, "Contribuiçâo para o estudo de alguns dos mosaicos da villa romana de Pisôes", Arquivo de Beja II, serie 2. ${ }^{\mathrm{a}}$, 1985, pp. 95-135 M.J. Duran, «Algunas consideraçoes sobre a iconografia das estaçoes do ano: a villa romana de Pisoes", Homenaxe a Ramón Lorenzo, Vigo 1998, pp. 445-454; M. Pessoa, «Renouveau artistique des mosaïques romaines représentant les saisons au Portugal», La Mosaïque Gréco-romaine IX,2, Roma 2005, pp. 1042-1043, fig. 6. 


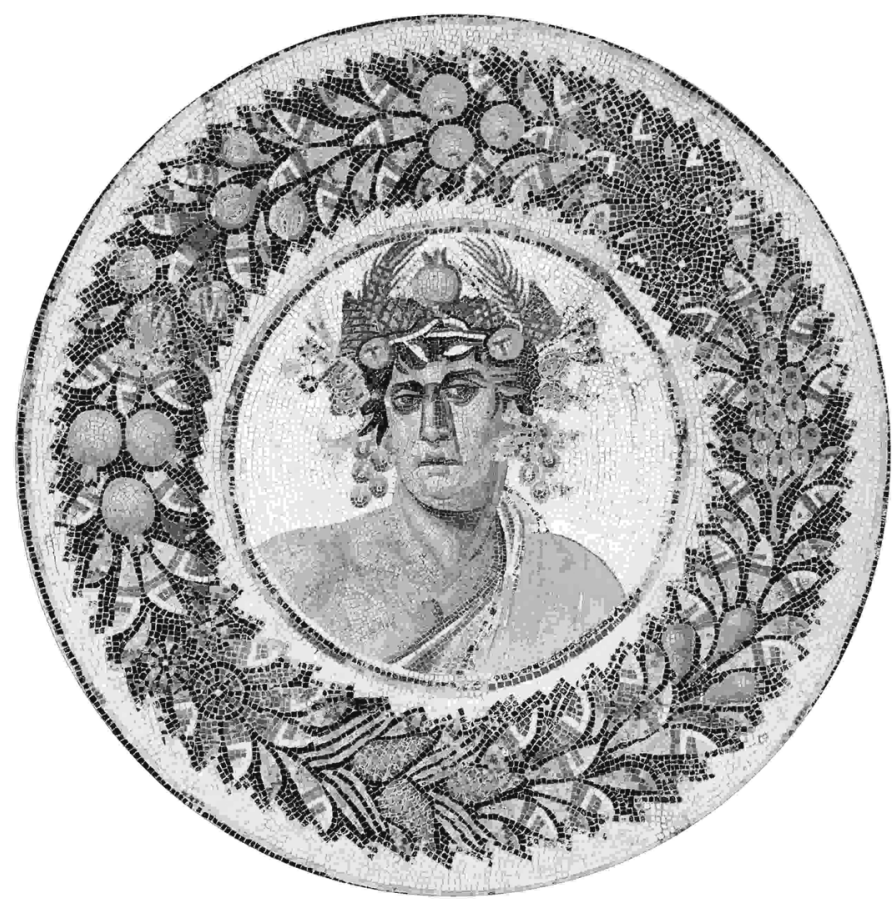

Fig. 2. Mosaico del Genio del Año de El Jem, Túnez. Mediados del siglo II.

cipios del siglo IV ${ }^{6}$, con uvas, espigas, flores, manzanas y cítricos entre otros en la guirnalda, con la particularidad de que estos grupos de xenia coinciden con las estaciones de las esquinas y con las diferentes xenia que aparecen en los espacios cuadrangulares y en las lunetas (infra). Mosaico de los Aurigas de Augusta Emerita, de la segunda mitad del siglo $\mathrm{IV}^{7}$, con flores y frutas, entre las cuales se aprecian manzanas como en el pavimento toledano. Mosaico de la villa de Arellano, Arróniz (Navarra), que se conserva en el Museo Arqueológico Nacional y se fecha a fines del siglo III o comienzos del IV ${ }^{8}$, con berenjenas y otros frutos en la guirnalda. Pavimento de la habitación 5 de la villa de El Ramalete (Navarra), de principios del siglo IV ${ }^{9}$, que se conserva en el Museo Arqueológico de Navarra, con frutos no identificados en la guirnalda y cestos de frutos indeterminados en los ángulos como alegorías de las estaciones (infra).

6 J.M. Blázquez, Mosaicos romanos de la Real Academia de la Historia, ciudad Real, Toledo, Madrid y Cuenca, CMRE V, Madrid 1982, pp. 36- 40, n. ${ }^{\circ} 26$, láms. 20-23, 47-48.

7 A. Blanco, Mosaicos romanos de Mérida, CMRE I, Madrid 1978, pp. 45-46, n. ${ }^{\circ}$ 43, láms. 76-79.

8 J.M. Blázquez y M.A. Mezquiriz Mosaicos romanos de Navarra, CMRE VII, Madrid 1985, pp. 1522, n. ${ }^{\circ}$ 2, lám. 50; M.A. Mezquiriz, La villa romana de Arellano, Pamplona 2003, pp. 220- 227.

9 J.M. Blázquez y M.A. Mezquiriz op. cit. en nota 8, pp 69- 73, n. 45, fig. 11, láms. 41-42; D. Fernández Galiano, Mosaicos Romanos del Convento Cesaraugustano, Zaragoza 1987, pp. 110-111, n. ${ }^{\circ}$ 178, láms. L, LI. 


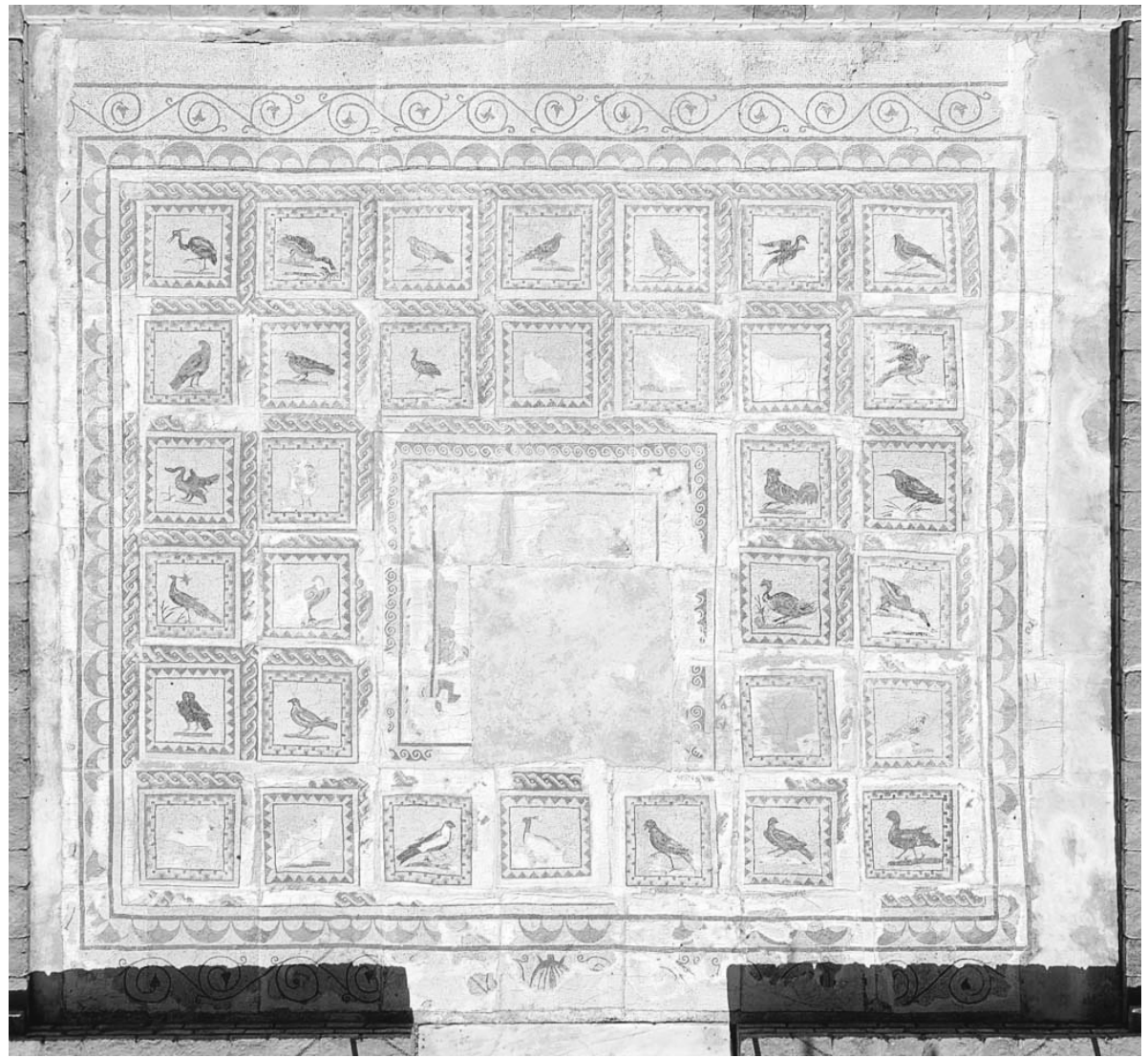

Fig. 3. Mosaico de los Pájaros de Itálica. Siglo ॥l (cortesía de J.M. Luzón).

Los paralelos más exactos para la corona de laurel de estos cinco mosaicos hispanos aparecen en el mosaico del Genio del Año y las Estaciones de la Casa de la Procesión dionisiaca de El Jem, de mediados del siglo $\|^{10}$ (Fig. 2), y en el del Dionisos adolescente de la Casa de Dionisos y Ulises en Dougga, de principios del siglo IV ${ }^{11}$, ambos encerrando el emblema central.

El tercer tipo, en la orla cuadrada del emblema, sería una variante del anterior y aparece, aunque muy deteriorado, en el mosaico de los Pájaros de Itálica, del siglo II, así como diferentes tipos de aves insertadas en una composición de cua$\operatorname{drados}^{12}$ (Fig. 3).

10 M. Blanchard-Lemée et alii, Sols de la Tunisie Romaine, Paris 1995,p. 286, figs. 17 y 18; D. Parrish, Season mosaics of Roman North Africa, Roma 1984, pp. 149-151, n. ${ }^{2}$ 26, láms. 34b-35, $37 b-38$.

11 M. Blanchard-Lemée et alii, op. cit. en nota 10, p. 287-288, fig. 72.

12 A. Parlade, «Excavaciones en Itálica. Campañas 1925-1932 »,. Memorias de la Junta Superior del Tesoro Artístico 127, 1934, pp. 11 y 18, lám. XV; R. Thouvenot, Essay sur la province Bétique, Paris 


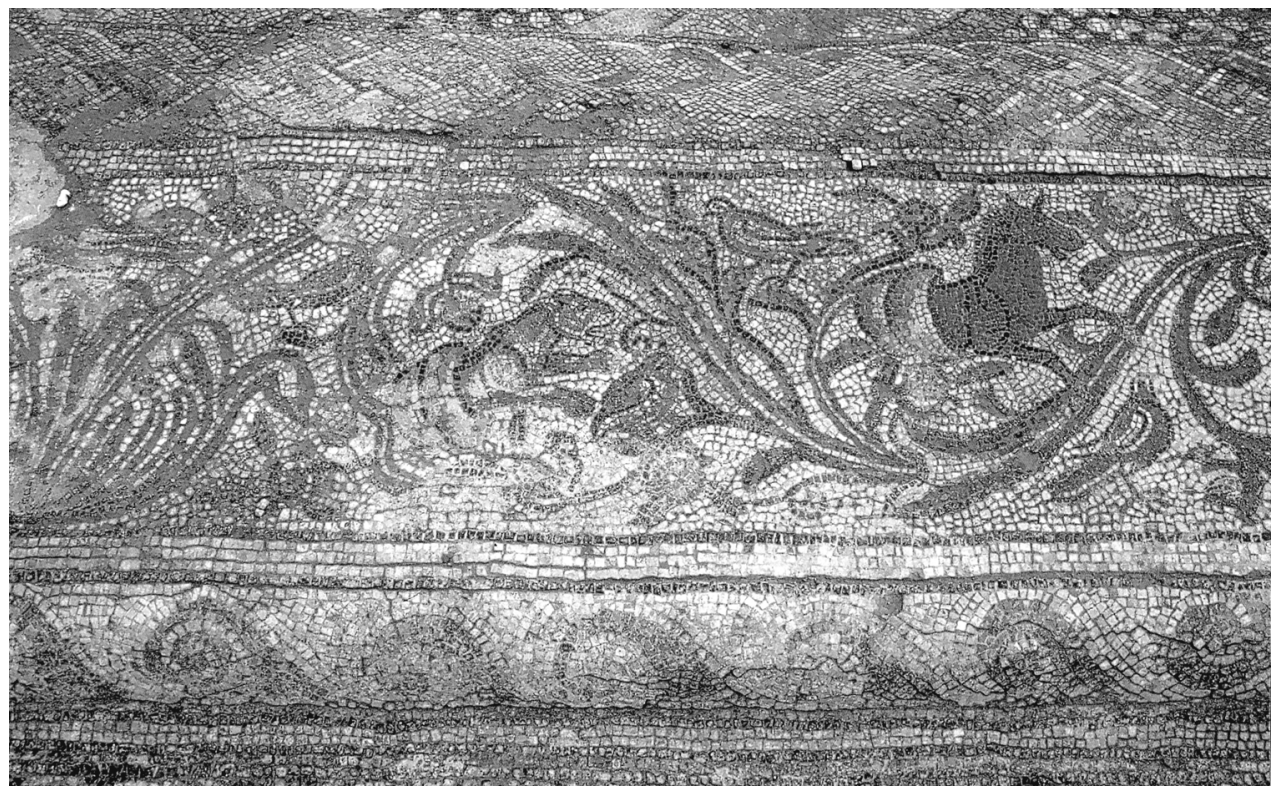

Fig. 4. Mosaico del oecus de la villa de Arróniz, Navarra. Siglo IV.

El cuarto tipo, decorando una figura geométrica, está representado por el mosaico de Quintos (Portugal), conservado en el Museo de Béja ${ }^{13}$, con un pez en una corona de laurel enmarcando un cuadrado.

\section{XENIA EN GUIRNALDAS DE FOLLAJE}

Se aprecian en tres mosaicos hispanos: pavimento del triclinium de la villa de Torre de Palma, Monforte (Portugal), del siglo $\mathrm{IV}^{14}$, con peras y racimo de uvas. Mosaico de la villa romana de Cornellà de Llobregat (Barcelona), fechado en el siglo $\mathrm{IV}-\mathrm{V}^{15}$, con una granada. Mosaico del escalón que da paso a la zona absidada del

1940, pp. 649- 650, fig. 170; J.M. Álvarez Martínez, « La iconografía de Orfeo en los mosaicos hispanorromanos", Estudios sobre iconografía. Actas del Homenaje a Alberto Balil, Guadalajara 1990, pp.; M. Duran, Iconografía de los Mosaicos Romanos en la Hispania Imperial, Barcelona 1993, pp. 51-54, lám. III,5; I.J. Jesnick, The image of Orpheus in roman mosaic. An exploration of the figure of Orpheus in Greco-Roman art and culture with special reference to its expresion in the medium of mosaic in late Antiquity, BAR International Series, 671, Oxford 1997, n. ${ }^{\circ} 34 a$, pp. 134- 135.

13 R. Serpa Pinto, Inventario, pp. 176-177, lám. V, 8; Museo Regional de Beja. Catálogo de algunas das principias peças, Beja, s.d., p. 10, núm. 16, con dibujo de reconstrucción del pavimento.

${ }_{14} \mathrm{M}$. Heleno, «A vill lusitan-romana de Torre de Palma (Monforte)», O Arqueólogo portugués IV, 1962, pp. 333-334, EST. G.

${ }_{15} \mathrm{X}$. Barral i Altet, Les mosaïques romaines et médiévales de la regio laietana (Barcelone et ses environs), Barcelona 1978, pp. 122- 124, láms. LXXIX y LXXX,1; J.M. Solias, El poblament ibérico-romà del curs inferior del Llobregat (Tesis Doctorales de la Universitat de Barcelona), Barcelona 1990, pp. 1277- 


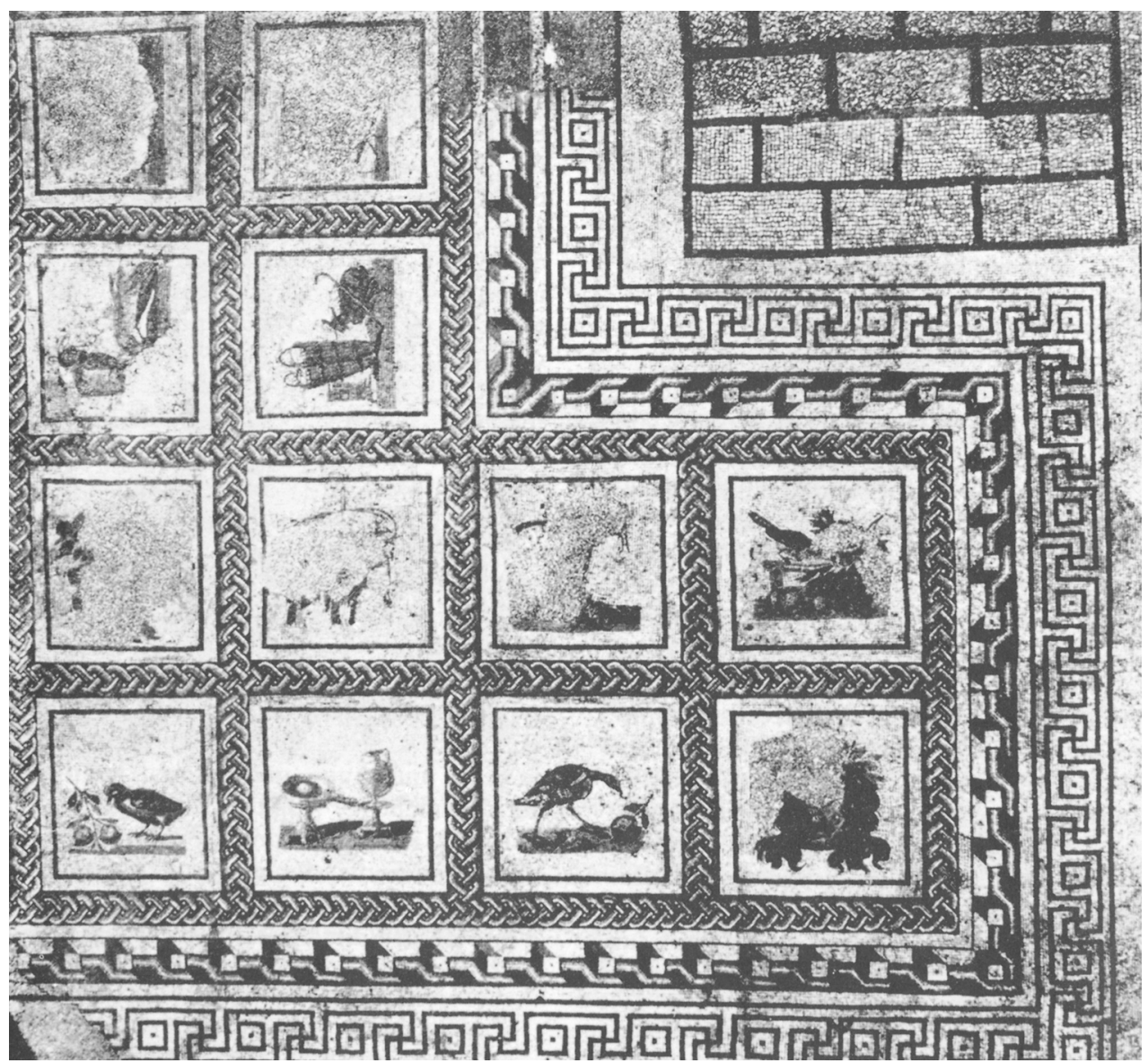

Fig. 5. Mosaico de Ostia, Siglo II.

oecus de la villa de Arróniz (Navarra), del siglo IV-V ${ }^{16}$, con frutos, flores y pájaros, además de otros animales como caballo, tigre, pantera y león ${ }^{17}$ (Fig. 4).

\section{XENIA ENCERRADAS EN DISTINTOS ESPACIOS GEOMETRICOS}

Las xenia se distribuyen en diferentes espacios geométricos: cuadrados, rectángulos, círculos, octógonos, arcadas.

1278, fig. 675; J. Bonamusa Roura, Los mosaicos de la Layetania romana, Curso de Doctorado de la UNED, Madrid 2003, pp. 8-9, lám. 1.

${ }_{16}$ M.A. Mezquiriz Irujo, op. cit. en nota 8, pp. 231-235.

17 Algunos animales tienen un significado simbolico, vid. P. Miguel, Dictionnaire symbolique des animaux, Paris 1992. 
En una composición a base de cuadrados se documenta en seis mosaicos: En el citado mosaico de los Pájaros de Itálica (Fig. 3). El mosaico, muy incompleto, del siglo II-III, de la calle Miguel de Cervantes de Écija, antigua Colonia Augusta Firma Astigi $^{18}$, localizado cerca del foro, en la zona Sur del cardo maximus, con un grupo de cuatro granadas. Fragmento de mosaico de los Villares, Quintana del Marco, León, del siglo $\mathrm{IV}^{19}$, con un faisán dentro de un cuadrado. Mosaico del peristilo interior de la Casa de la Huerta de Otero en Mérida, de finales del siglo II o comienzos del III20, con un pez o un molusco. Pavimento de murallas de una domus de la calle Suárez Somonte de Mérida, del siglo, con una perdiz ${ }^{21}$. Mosaico de la sala E de la villa urbana de Santa Vitoria do Ameixil (Estremoz, Alto Alentejo, Portugal), del siglo $\mathrm{IV}^{22}$, con diversos peces dentro de cuadrados. Pavimento de la villa de Vega de Ciego (Asturias), de comienzos del $v^{23}$, con peces aves afrontadas, crateras y diversas figuras geometricas.

El esquema compositivo dividido en pequeños cuadrados aparece por primera vez en un mosaico de Ostia, fechado hacia el año $127^{24}$ (Fig. 5), con una larga perduración como demuestra un pavimento de El Jem, de finales del siglo $\mathrm{II}^{25}$, y dos mosaicos italianos de Tor de'Schiavi de los Museos Vaticanos, fechados en la primera mitad del siglo IV ${ }^{26}$.

En una composición a base de rectángulos aparece en un mosaico de la basílica paleocristiana de Santa María de Tarrasa, de la segunda mitad del siglo $\mathrm{v}^{27}$, con delfines.

En el interior de un círculo se documenta en cuatro mosaicos: Pavimento de Córdoba de la Avenida de la Victoria, de finales del siglo $\|$ o comienzos del $\| 1^{28}$, ac-

18 F. Fernández Gómez, «Un conjunto musivario excepcional en Ecija», Revista de Arqueología XIX7207, 1998, pp. 32-41. G. López Monteagudo «Las casas de los extranjeros en la colonia Augusta Firma Astigi», L'Africa Romana XVI (Rabat 2004), 2006, p. 121, fig. 5.

19 J.M. Blázquez et alii, Mosaicos romanos del Museo Nacional, CMRE IX, Madrid 1989, pp. 48-49, láms. 27 y 47; VVAA, Mosaico Romano del Mediterráneo, Madrid 2001, p. 46.

20 A. Blanco, op. cit. en nota 7, p. 49, n. $^{\circ} 56$, lám. 87.

21 G. Méndez Grande, «Restos de una domus con pavimento musivo y su posterior evolución. Intervención arqueológica realizada en el solar n. ${ }^{\circ} 83$ de la c/ Suárez Somonte», Memoria 7, 2004, p. 264, láms. 3-4

${ }^{22}$ L. Chaves, «A villa de Santa Vitória do Ameixial. Excavaçôes em 1915-1916», O Arqueologo Portugués 30, pp. 14-117, est. IV, fig. 16.

23 J.M. Blázquez et alii, Mosaicos romanos de León y Asturias, CMRE X, Madrid 1993, pp. 51-53, n. ${ }^{\circ}$ 32, láms. 17-20.

24 G. Becatti, Mosaici e pavimenti marmorei. Scavi di Ostia IV, Roma 1961, n. ${ }^{\circ}$ 238, láms. CIII-CIV, CCXXII-CCXXIII.

25 Picard, BAC, 1950, p.156, lám. IX; K.M.D. Dunbabin,, The Mosaics of Roman North Africa. Studies in iconography and Patronage, Oxford 1978, pp. 125, 170, foto 118.

${ }^{26}$ G. Becatti, op. cit. en nota 24, n. ${ }^{\circ} 315$, lám. Cll; M. de Franceschini, Villa Adriane, Roma 1991, n. ${ }^{\circ}$ 32-33, p. 349, lám. 50; Vid. nota 24.

27 X. Barral i Altet, op. cit. en nota 15, núm. 144, pl. XC.

28 A. Marcos Pous y A.M. Vicent Zaragoza, «Investigación, técnicas y problemas de las excavaciones en solares de la ciudad de Córdoba y algunos resultados topográficos generales», Arqueología de las ciudades modernas superpuestas a las antiguas, Zaragoza 1985, p. 240; M. Moreno Gonzalez, Aproximación al estudio de la decoración musivaria en Colonia Patricia Corduba, Memoria de Licenciatura, Univ. de Córdoba, Córdoba 1995, pp. 47- 49, lám. 11. 


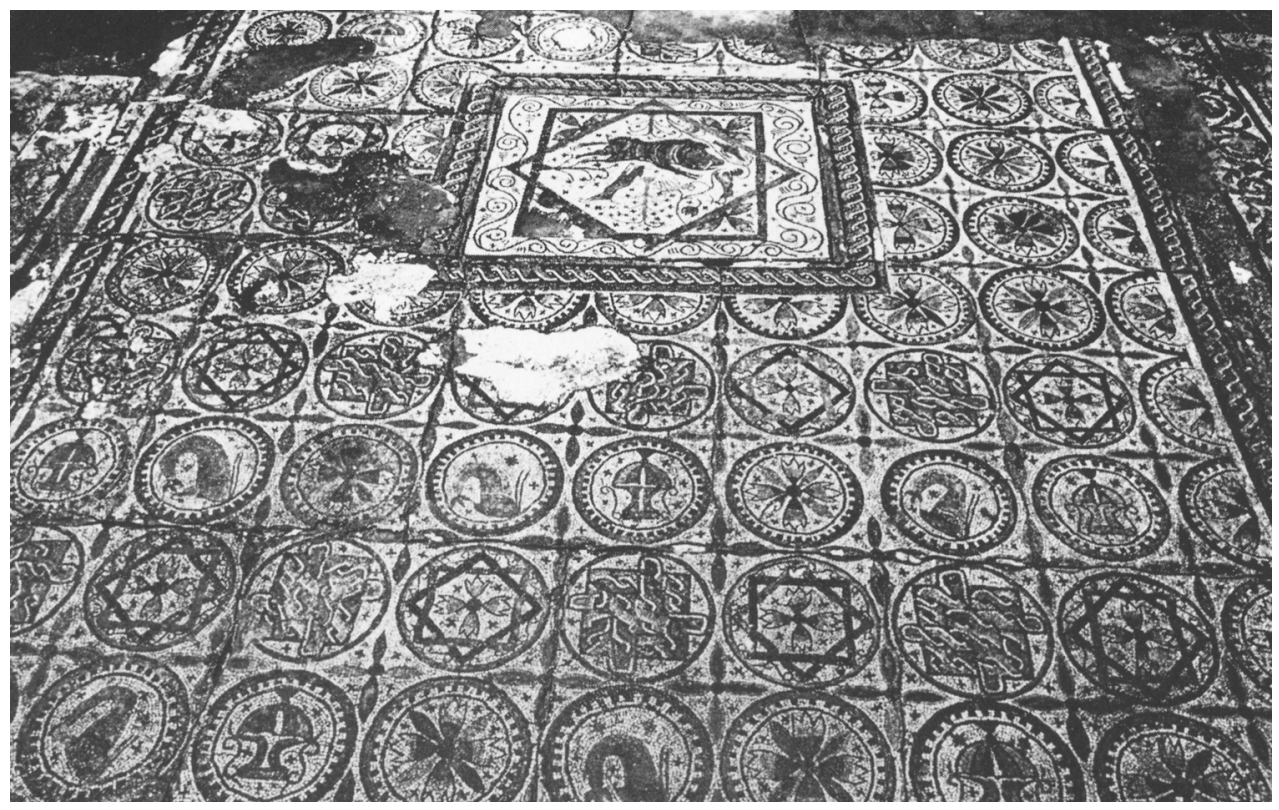

Fig. 6. Mosaico de la Caza del jabalí, Mérida. Siglo v.

tualmente expuesto en el Museo Arqueológico de dicha ciudad, en el que se representa un ramo con cuatro granadas. Mosaico con peces de la Casa del Anfiteatro de Mérida, del siglo $1 \mathrm{I}^{29}$. El de Artieda de Aragón, de la segunda mitad del siglo $\mathrm{IV}^{30}$, con una fuente en el emblema y peces, aves y cestos con flores en los círculos. Y el pavimento de la Caza de jabalí, también de Mérida, siglo $\mathrm{V}^{31}$, con peces, flores, cráteras y diversos motivos geométricos (Fig. 6).

En una composición a base de hexágonos está documentado en el mosaico de cacería de la villa de Campo de Villavidel (León), del siglo IV ${ }^{32}$, con peces (Fig. 7).

En una composición a base de octógonos figura en cuatro mosaicos: en el pavimento de Opora, hallado en el año 2002 en una domus de Mérida, posiblemente en del oecus o tablinum, de la actual calle Sagasta, fechado a finales del siglo III-IV ${ }^{33}$, con un cesto de frutos rodeado por unas guirnaldas. Mosaico de la antesala del oecus de la villa de Materno en Carranque, Toledo, fechado en el si-

29 A. Blanco, op. cit. en nota 7, n. ${ }^{\circ} 31$, láms. 57-62.

30 D. Fernández-Galiano, op. cit. en nota 9 , n. ${ }^{\circ} 20$, pp. 30-32, láms. XI-XII.

31 J.M. Álvarez Martínez, Mosaicos romanos de Mérida. Nuevos hallazgos, Mérida 1990, pp. 60-65, n. ${ }^{\circ}$ 10, fig. 4, láms. 27-29.

32 J.M. Blázquez et alii, op. cit. en nota 23, n. ${ }^{\circ 5}$, pp. 21-23, láms. 4-5, 24-25.

33 P.D. Sánchez Barrero, «Trabajo desarrollado por el Equipo de Seguimiento de Obras durante el año 2002", Mérida. Excavaciones Arqueológicas 8, 2005, p. 445, fig. 6; G. López Monteagudo, Un nuevo mosaico de Augusta Emerita con la representación alegórica de Opora», Assaph 10-11, 2005-2006, pp. 347-364. 


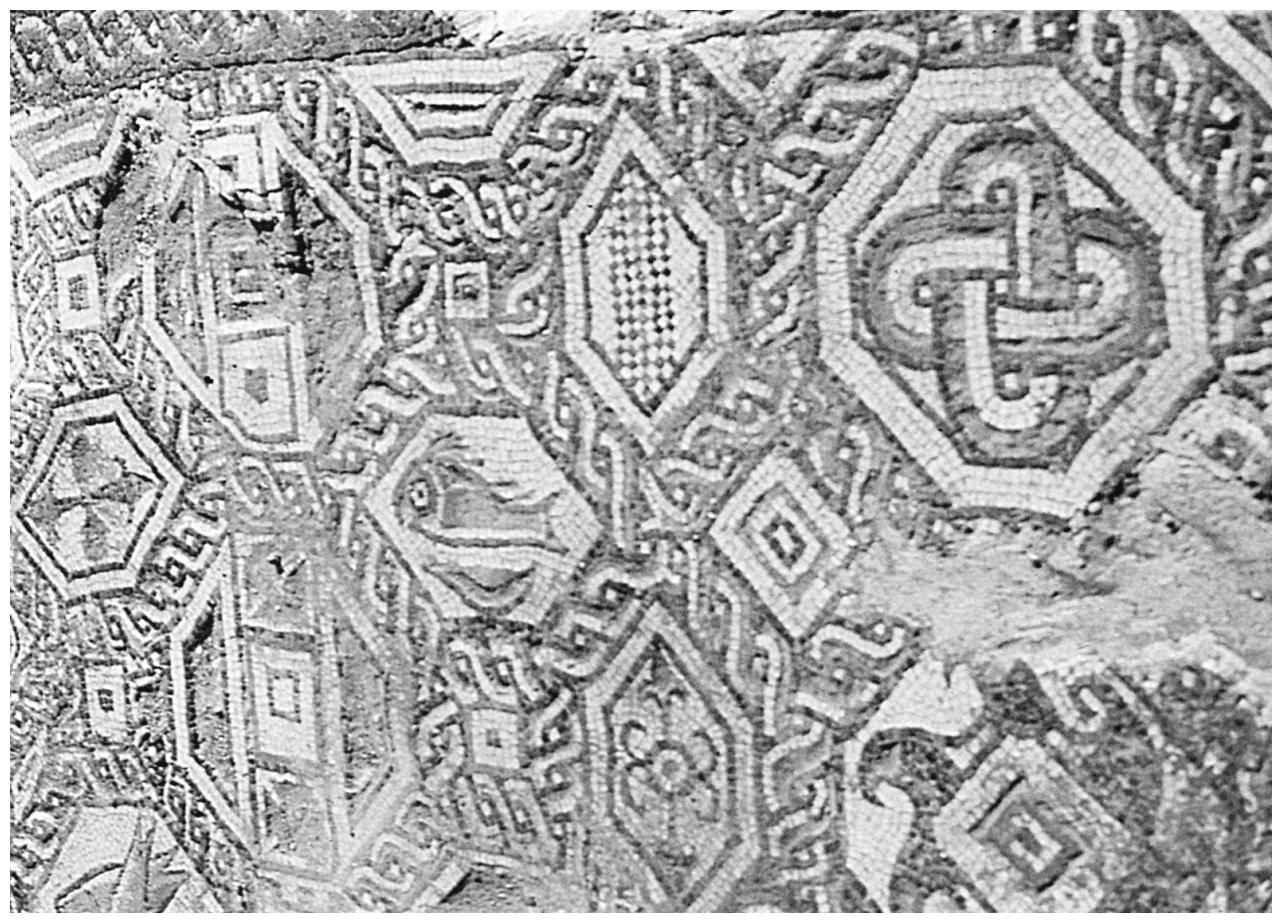

Fig. 7. Mosaico de cacería de la villa de Campo de Villavidel, León. Siglo Iv.

glo $\mathrm{IV}^{34}$, con cestos de frutas, posiblemente cítricos, cráteras con pie y peces (Fig. 8). Mosaico muy deteriorado de Pedras d'el Rei (Tavira, Portugal) ${ }^{35}$ con peces dentro de octógonos. Pavimento de la villa de San Martín de Losa (Burgos), habitación $\mathrm{C}$, fechado a finales del siglo IV o comienzos del $\mathrm{V}^{36}$, con tallos de vid, coronas de laurel, racimos de uvas, así como aves, peces, delfines y monstruos marinos.

La asociación de figuras mitológicas del repertorio marino en un contexto de xenia no es desconocido en la musivaria romana, aparece en un mosaico de Salzburgo datado en el siglo $11^{37}$, con representaciones de Nereidas en el medallón central, y en el mosaico de Saint-Romain-en-Gal, de principios del siglo $\|^{38}$, con monstruo marino y composición semejante al pavimento burgalés (Fig. 9).

34 D. Fernández-Galiano, «La villa de Materno, Carranque, Toledo». Revista de Arqueología 127, 1991, pp. 29-30; D. Fernández-Galiano, «The villa of Maternus at Carranque Fifth International Colloquium on ancient mosaics (Bath, England 1987)», Ann Arbor 1994, p. 205, fig. 10.

35 Mosaicos romanos na Coleçcôes do Museo Nacional de Arqueologia, Lisboa 2005, pp. 32-33.

36 G. López Monteagudo et alii, Mosaicos romanos de Burgos, CMRE XII, Madrid 1998, pp. 30- 32, n. ${ }^{\circ} 14$, fig. 7 , láms. 15-18.

37 W. Jobst, Antike Mosaikkunst in Osterreich, Wien 1985, pp. 58-60, lám. 6.

38 J. Lancha, Recueil general des mosaïques de la Gaule, III, Province de Narbonnaise, 2, Vienne, París 1981, n. ${ }^{\circ} 395$, pp. 260-274, láms. CXLVIIa, CXLIX. 


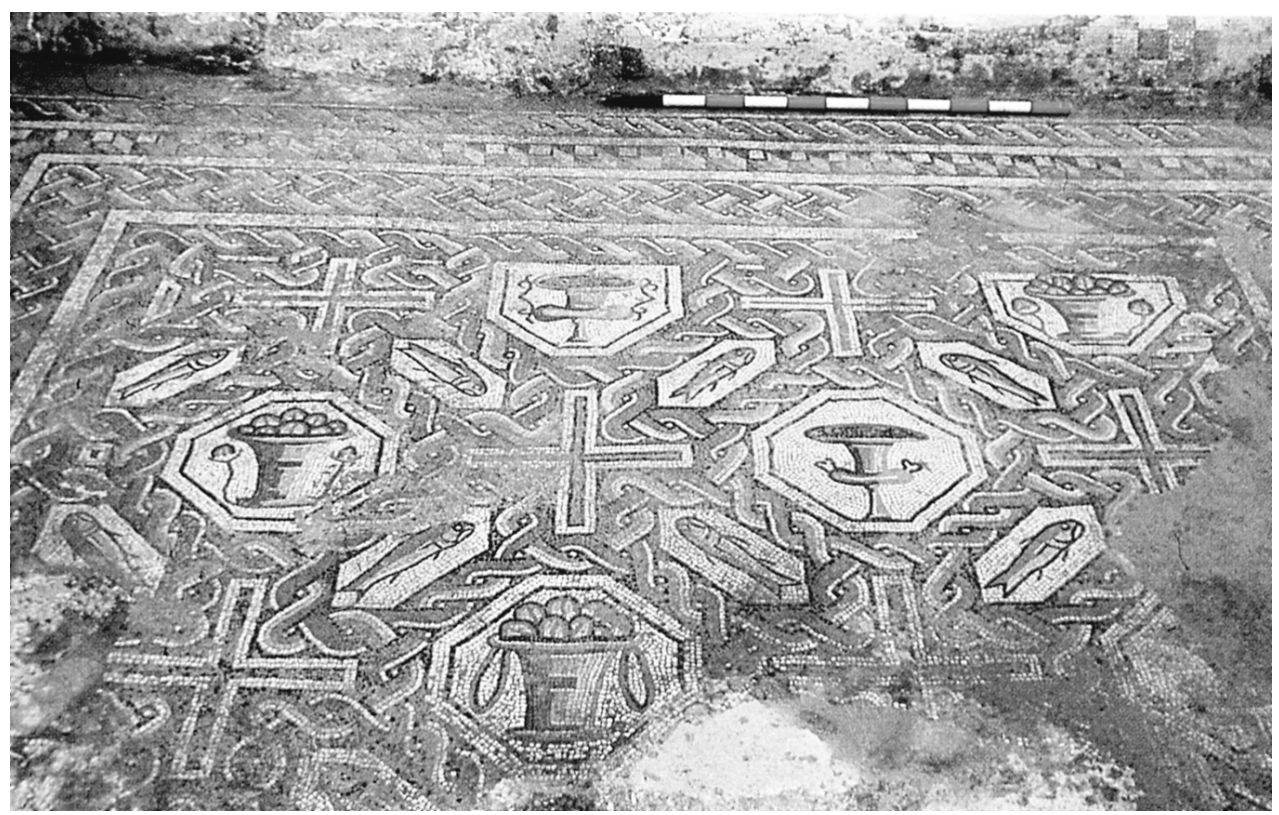

Fig. 8. Mosaico de Carranque, Toledo. Siglo Iv.

En una composición a base de diversas figuras geométricas se documenta en seis mosaicos: el de la Medusa, de la Casa de Otero en Mérida, de finales del siglo ॥ o comienzos del \|\|$^{39}$, que presenta cuadrados con pájaros y máscaras, rectángulos con un pez y hexágonos con pavos (Fig. 10). El mosaico de la domus de las columnas rojas de Sisapo-La Bienvenida (Almodóvar del Campo, Ciudad Real, del siglo $11-1 I^{40}$, mediante rombos con diversos peces y pulpos o calamares, cuadrados con crateras y máscaras como el pavimento anterior ${ }^{41}$. Mosaico de El Ejido, Almeria, del siglo $\mathrm{II}^{42}$, en un esquema compositivo de cuadriculado de círculos y targentes que determinan octógonos ${ }^{43}$, composición que pertenece al grupo «Kreissystem IV b» de Salies ${ }^{44}$; en los círculos aparecen aves, en los triángulos de

39 A. Blanco, op. cit., en nota 7, p. 49, n. ${ }^{\circ} 57$, láms 88- 90.

40 C. Guiral Pelegrín y M. Zarzalejos Prieto, «Les peintures romaines dans la capitale du cinebre hispanique», Dossier d Archéologique 318, Nov./déc. 2006, pp. 40 y 46; EADEM «La decoración pictórica de la domus de las columnas rojas de Sisapo-La Bienvenida (Almodóvar del Campo, Ciudad Real)», en J.M. Maillo y E. Baquedano (eds.), Miscelánea en Homenaje a Victoria Cabrera. Zona Arqueológica 7, vol. II, 2006, p. 140, fig. 9.

41 El carácter dionisiaco de este mosaico queda bien patente en la presencia de cráteras y de máscaras, remarcando la asociación de xenia y de imágenes dionisiacas tan frecuente en la musivaria norteafricana, vid. S. Gozlan, op. cit. en nota 2; C. Balmelle et alii, op. cit. en nota 2, pp. 75-78.

42 G. López Monteagudo, et alii, «Recientes hallazgos de mosaicos romanos figurados en Hispania», La Mosaïque Gréco-Romaine VII, t. 2, Túnez 1999, p. 520, lám. CLXXIV.

43 C. Balmelle et alii, Le décor géometrique de la mosaïque romaines, Paris 2000, n. 236 b-c.

44 G. Salies, «Untersuchungen zu den geometrischen Gliederungsschemata römische Mosaiken», Bonner Jahrbücher 174, 1974, p. 16, 165-167. 


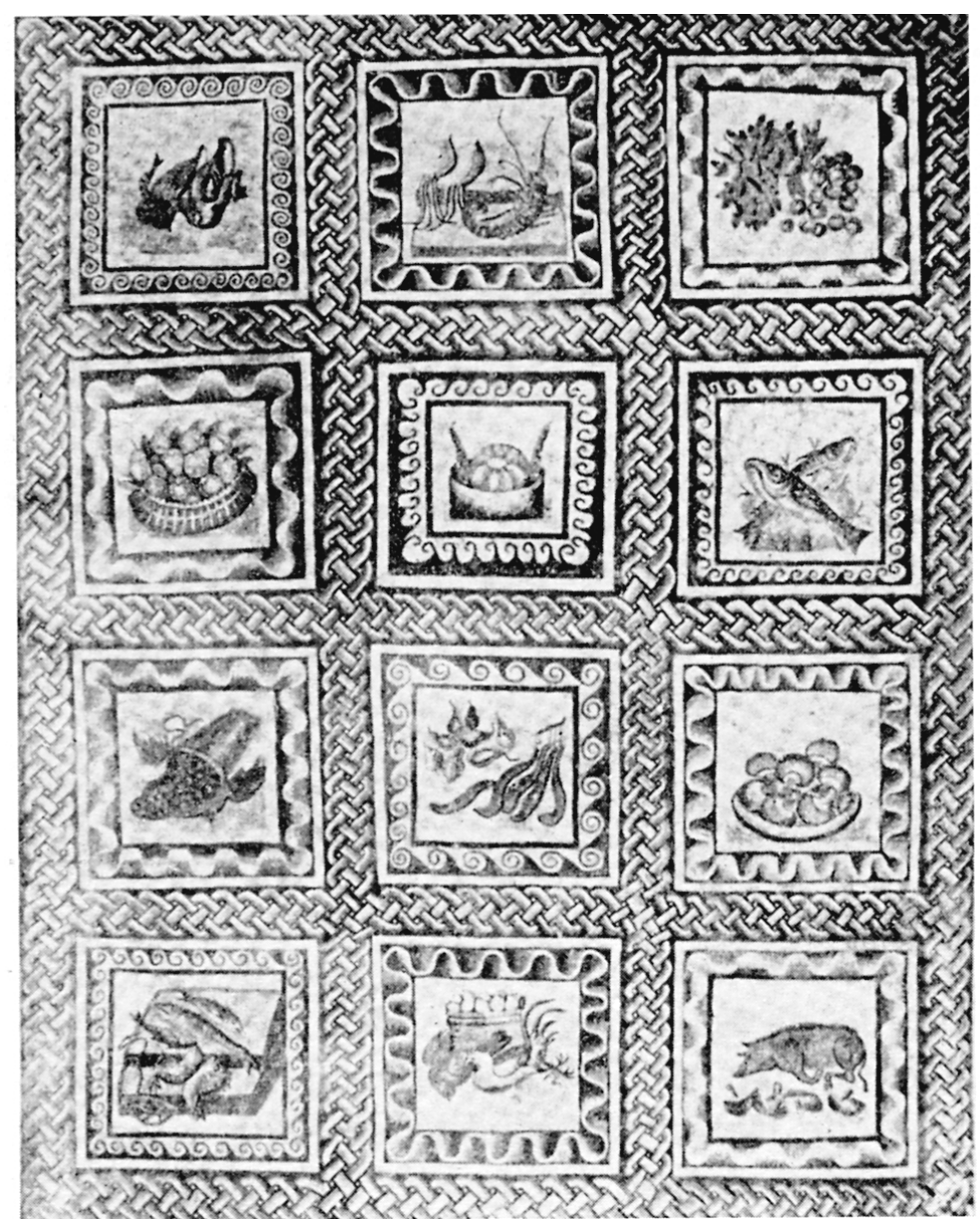

Fig. 9. Mosaico de Saint-Romain-en-Gal, Francia. Principios del siglo III.

las esquinas zarcillos de vid, así como motivos báquicos (pantera, fauno, satiro, medusa, cráteras, máscaras...). Mosaico de Sasamón en Burgos, de finales del siglo II- comienzos del III ${ }^{45}$, con un tritón en el octógono central, en los octógonos laterales decorados con otros animales marinos (ciervos, caballo, grifo, pantera), como en el pavimento de San Martín de Losa, en los hexágonos figuran peces y distintas clases de pájaros y en el resto de las figuras geométricas aparecen otros motivos. Mosaico de la habitación XX de la villa de Quintanilla de la Cueza, Palencia, de finales del siglo III- mediados del IV ${ }^{46}$, con parejas de peces en los octó-

45 J.A. Abásolo y R. García., Excavaciones en Sasamón (Burgos), EAE 164, Madrid 1993, págs. 179- 192, fig. 95, láms. XIX- XXVI; G. López Monteagudo et alii, Mosaicos romanos de Burgos CMRE XII Madrid 1998, pág. 32, n.․ 159, fig. 8, láms. 19-20 y 44.

46 M.A. García Guinea, La villa romana de Quintanilla de la Cueza (Palencia). Memoria de las excavaciones 1970-1981, Salamanca 2000, pp. 251-254, lám. 295. 


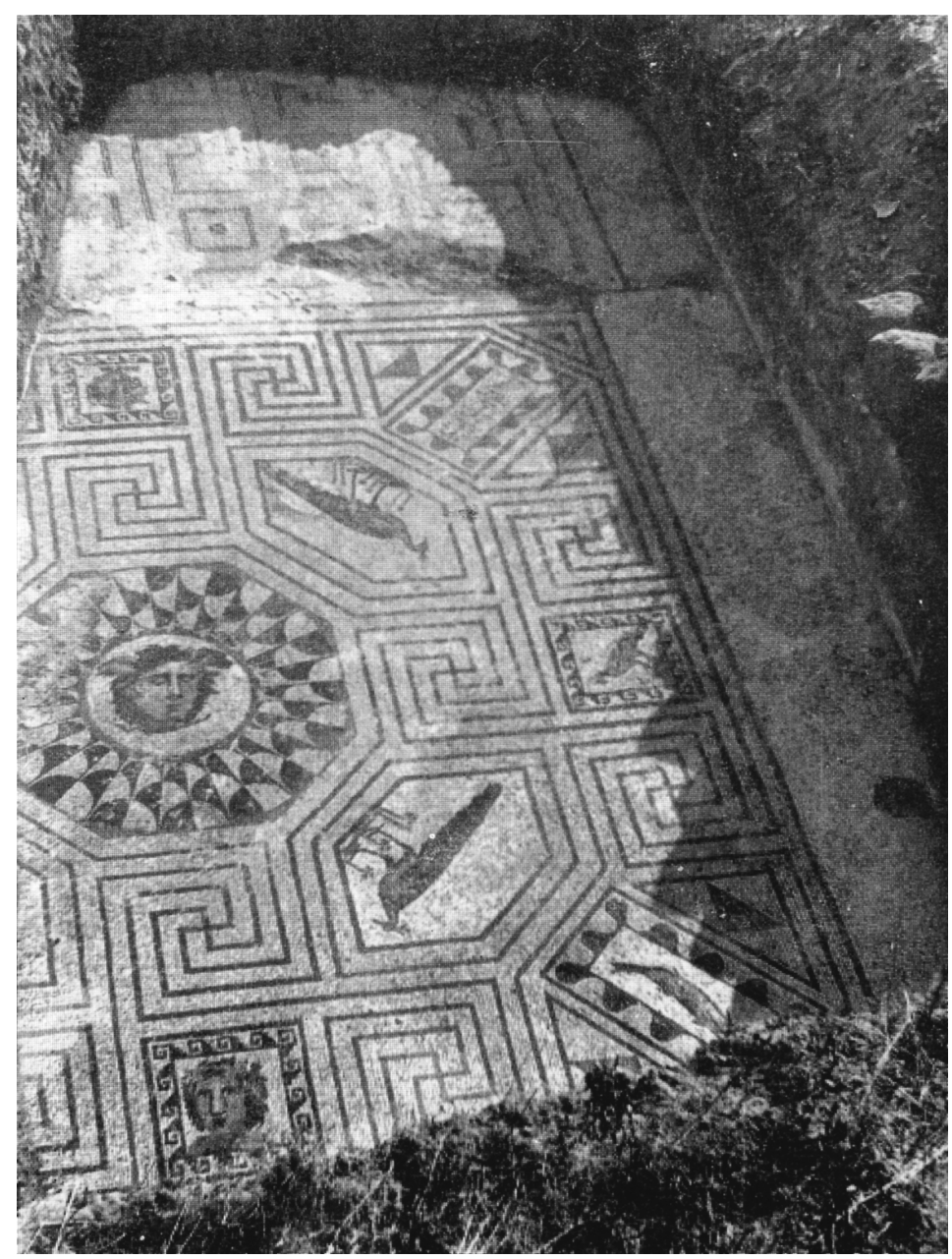

Fig. 10. Mosaico de la Casa de Otero, Mérida. Finales del siglo II- principios del III.

gonos y un pez en los hexágonos (Fig. 11). Igualmente se encuentra en el arte cristiano como en el mosaico de la sacristía de la basílica bizantina de Córdoba ${ }^{47}$, de mediados del siglo vi, con peces en los octógonos y en los círculos aparecen aves, granadas, recipiente metálico lleno de agua y cesto con panes.

Las xenia en arcadas pueden representarse tanto en simples arcadas aisladas como en una composición de arcadas, o composición ortogonal de escamas adyacentes.

47 P. Marfil Ruiz, La iglesia de Santa Catalina del antiguo convento de Santa Clara (Córdoba). Aspectos Arqueológicos, Patrimonio y ciudad. Jornadas Europeas de Patrimonio 1996, Córdoba 1996. 


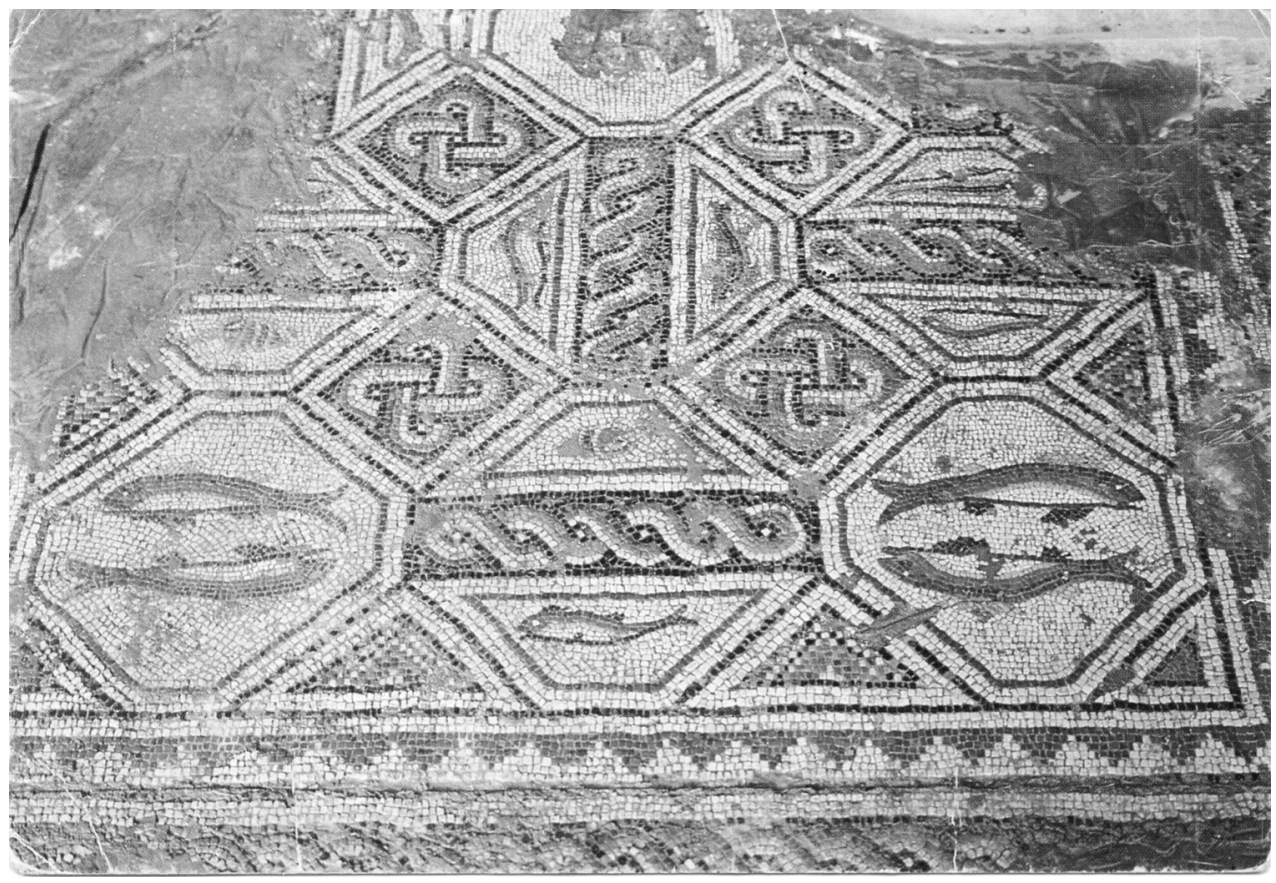

Fig. 11. Mosaico de peces de la villa de Quintanilla de la Cueza, Palencia. Finales del siglo III-mediados del IV.

En el primer tipo, arcadas simples aisladas, aparece en el mosaico cinegético de Thalassius, hallado en uno de los cubicula de una domus de Córdoba, fechado en la segunada mitad del siglo $\mathrm{IV}^{48}$ (Fig. 12). A cada lado, en medio de la cenefa de meandros, figura una arcada con un ave, identificándose la paloma, el pato y el pavo.

El segundo tipo, en composición de arcadas, aparecen en dos variantes, una en cables arqueados y otra en guirnaldas de laurel entrelazadas.

La primera variante se encuentra en el mosaico del pasillo $O$. del peristilo de la villa de El Romeral, Albesa, Lérida, de la segunda mitad del siglo IV ${ }^{49}$, en cuyas arquerías figuran alcachofas, cestos con frutas como en el mosaico de Carranque (supra), además de otros motivos como aves sobre ramos, capullos con hojas, flores y tiestos agallonados con pie.

La segunda variante figura en el mosaico del oecus de la villa del Soto de Ramalete, Tudela (Navarra), del siglo IV ${ }^{50}$, con ramos de flores y frutos como liliáceas,

48 F. Murillo Redondo y J.R. Carrillo Díaz-Pinés, «El mosaico de Thalassius en Corduba», La Mosaïque Gréco-Romaine VII, t. 2, Túnez 1999, pp. 535-537, láms. CLXXXIV.

49 J.M. Blázquez et alii, Mosaicos romanos de Lérida y Albacete, CMRE VIII, Madrid 1989, pp. 1415, láms 1,2 y 20.

50 J.M. Blázquez y M.A. Mezquiriz, op. cit. en nota 8 pp. 61-63, n. ${ }^{\circ}$ 43, fig. 9, lám. 55 (foto en portada); D. Fernández-Galiano, op. cit. en nota 9, p. 111, n. ${ }^{\circ} 179$, lám. LII M. Guardia Pons, Los mosaicos 


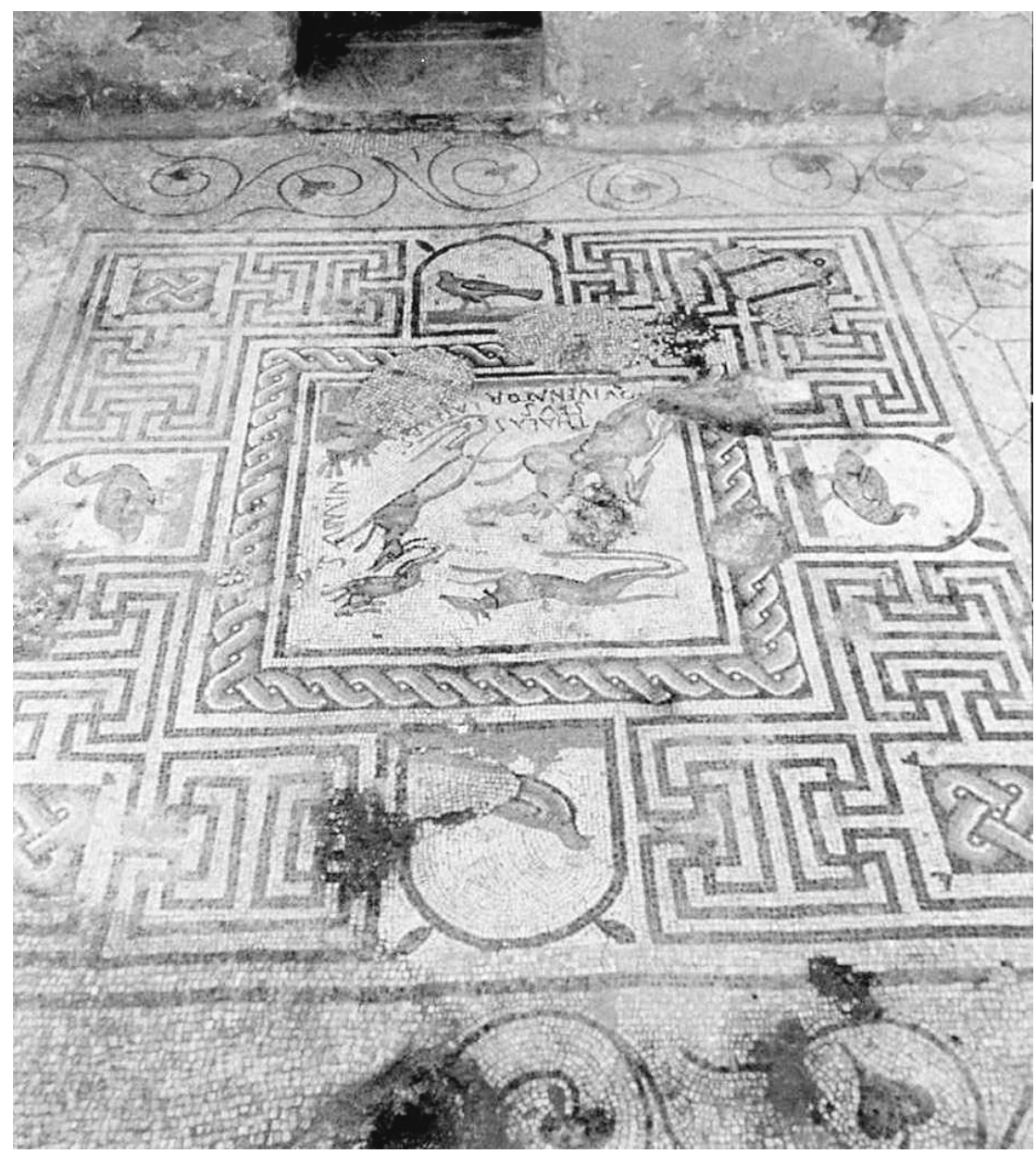

Fig. 12. Mosaico de Córdoba. Segunda mitad del siglo Iv.

campánulas, manzanas, peras y granadas, frutas todas ellas frecuentes en el repertorio de xenia como se aprecia en los anteriores pavimentos. En la guirnalda inferior aparece un delfín nadando.

\section{XENIA EN COMPOSICIÓN LIBRE}

Las xenia en composición libre se utilizan dos modelos diferentes, uno aparece en el mismo emblema y otro en el friso:

de la antigüedad tardía en Hispania. Estudios de iconografía, Barcelona 1992, pp. 101-106; G. López Monteagudo, "Las riquezas de las aguas en los mosaicos. Aspectos de la economía hispano-romana», L'Africa Romana XVII. En prensa. 


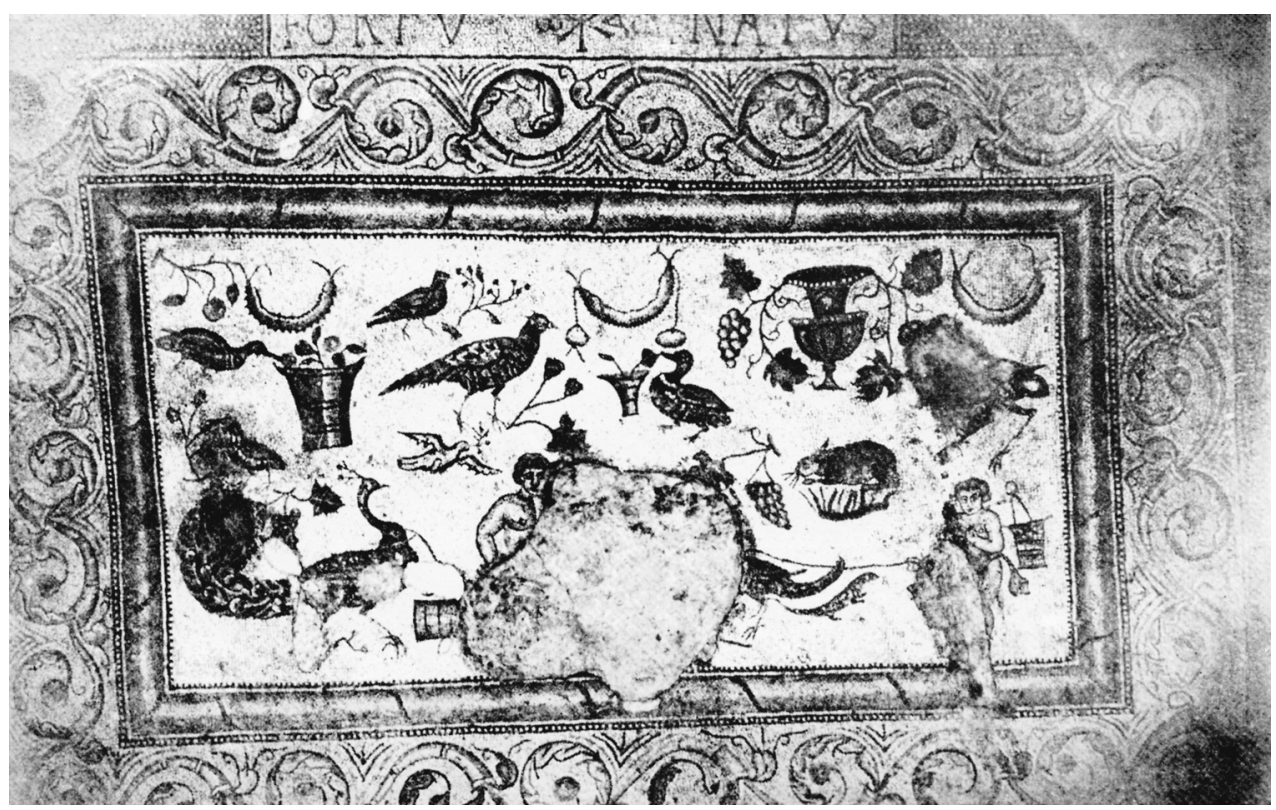

Fig. 13. Mosaico de Fortunatus de la villa de Fraga, Huesca.

Al primer grupo, en el mismo emblema, pertenecen, con exactitud, dos pavimentos y, posiblemente, otro. Uno de ellos es el mosaico de circo de Itálica, de finales del siglo III o principios del IV, conocido a través de un dibujo de A. Labor$\mathrm{de}^{51}$, con peras, un racimo de uvas y varias cidras. El otro pavimento es el de Fortunatus de la villa de Fraga, Huesca, que pavimentaba una habitación de prestigio, fechado a mediados del siglo $\mathrm{IV}^{52}$, con varios motivos de xenia dispersos, aves, guirnaldas, erotes, flores, frutos... (Fig. 13). El esquema compositivo de este pavimento aragonés, aunque es poco frecuente, aparece en el mosaico de la Casa n. ${ }^{\circ} 7$ de Bulla Regia, del siglo III-II ${ }^{53}$, y en el mosaico de la gacela de la Casa del Triunfo de Dionisos, en Sousse que decora la exedra del peristilo, fechado en el siglo ${ }^{1 I^{54}}$ (Fig. 14).

El mosaico de los Villares, León del que se conserva un fragmento, aparece tres perdices ${ }^{55}$, que posiblemente estaría representadas en el emblema (Fig. 15).

51 A. Blanco, Mosaicos romanos de Itálica, CMRE II, Madrid, 1978, pp. 55-56, n. ${ }^{\circ}$ 43, láms. 61-73 y 75; J. Polzer, Circus Pavements, Nueva York 1963, pp. 119 ss.; J.H. Humphrey, Roman Circuses, Londres 1986, pp. 233 ss; G. López Monteagudo, « Mosaicos romanos de circo y anfiteatro», VI Coloquio Internacional sobre Mosaico Antiguo (Palencia-Mérida 1990), Guadalajara 1994, pp. 348-349.

52 D. Fernández-Galiano, op. cit. en nota 9, pp.86-88, n. ${ }^{\circ}$ 122, láms. XXXVII-XXXVIII,1.

53 A. Beschaouch, R. Hanoune, Y. Thébert, Les ruines de Bulla Regia, Roma 1977, p. 42, fig. 31; R. Hanoune, Les mosaïques: 1, École Française de Rome, Roma 1980, figs. 127,130-131.

54 L. Foucher, Inventaire des Mosaïques de Sousse, Túnez, p.46, lám. XXII; D. Parrish, op. cit. en nota 9, n. ${ }^{\circ} 36$, pp. 28-29 y 32; M. Blanchard_Lemée et alii, op. cit. en nota 10, p. 287, fig. 47.

${ }_{55}$ J.M. Blázquez et alii, op. cit. en nota 19, pp. 48-49, lám. 27; VV.AA, op. cit. en nota 19, p. 48. 


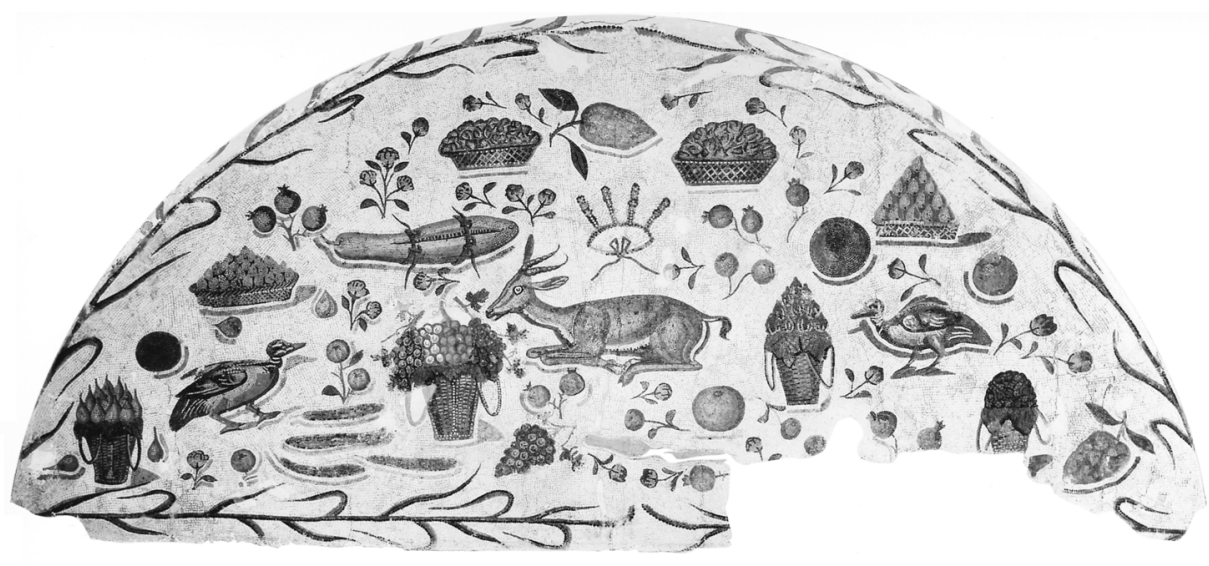

Fig. 14. Mosaico de la Casa del Triunfo de Dionisos, Sousse, Túnez. Siglo III.

El segundo grupo, en el friso, se documenta en un ejemplar excepcional entre los mosaicos de xenia, no solo de Hispania sino del resto del Imperio romano. Se trata del pavimento en blanco y negro de la villa de Marbella, de finales del siglo I 0 comienzos del II, procedente de un patio porticado ${ }^{56}$. En él se representa en frisos lineales, que bordearían el esquema central, un bodegón con variada exposición de alimentos y objetos de cocina (Fig. 16).

\section{XENIA COMO CESTOS DE FRUTOS ESTACIONALES}

Las xenia con carácter estacional se utilizan de dos formas diferentes, una como alegorías de las estaciones y otra como frutos estacionales asociados a las mismas.

Como alegorías de las estaciones, se documentan en tres mosaicos hispanos: pavimento de El Ramalete (Castejón, Navarra) (supra); mosaico de Diana de la viIla de Comunión, Álava, de mediados del siglo III o segunda mitad del IV 57 localizado en una habitación cuadrada y con ábside, con la figura de la diosa Diana en el centro y en los ángulos tres cestos de frutas, manzanas, peras y cerezas, y un cuadrado con una cruz central; en el mosaico de la villa de Pisões (Beja, Portugal) (supra), aparecen en las lunetas aves dentro de un círculo, aves enfrentadas a un cántaro, aves picoteando un racimo de uvas, un cesto de flores.

56 C. Posac Mon, El mosaico romano de Marbella, Málaga 1963; ID., «La villa romana de Marbella», Noticiario Arqueológico Hispano I, 1972, pp. 98, 100, lám. II,2; J.M. Blázquez, op. cit. en nota 3, pp. 8183, n. ${ }^{55}$, fig. 22-23, láms 62-66; A. Balil Illana, «Un bodegón en mosaico hallado en Marbella (Málaga)», Baetica 6, 1983, pp. 161-174.

57 M. Torres, «Los mosaicos descubiertos en el siglo XVIII en la villa de Cabriaza (Alava)», Estudios de Arqueología Alavesa 10, 1981, pp. 321-327, fig. 5 D. Fernández-Galiano, op. cit. en nota 9, pp.133134, n. ${ }^{\circ} 206$, lám. LXXV. 


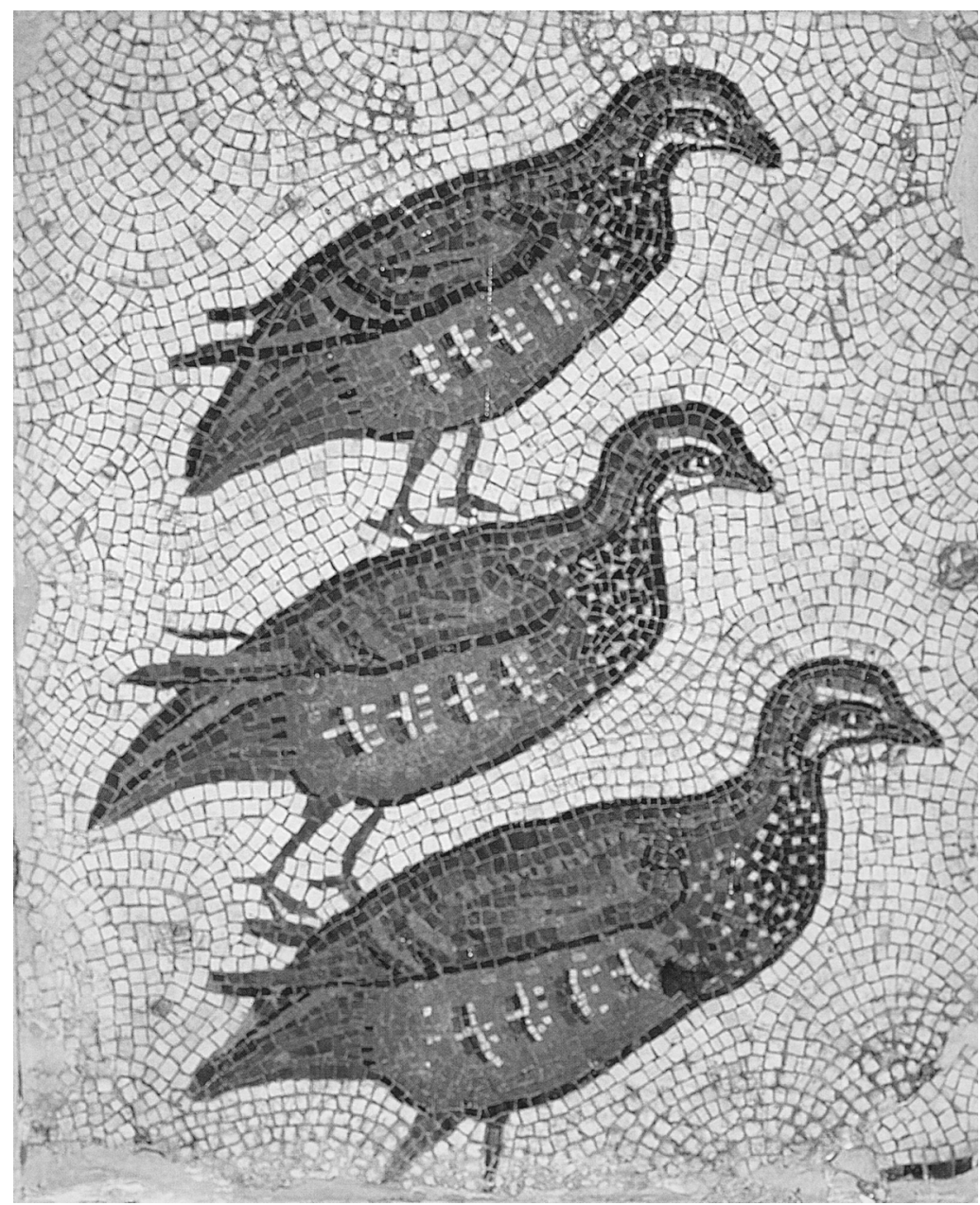

Fig. 15. Mosaico de los Villares, Quintana del Marco, León. Siglo IV.

Xenia asociadas a las estaciones figuran en dos mosaicos hispanos: pavimento de la Vega Baja de Toledo (supra) y mosaico de la Colonia Augusta Firma Astigi, del siglo II-III, descubierto recientemente cerca del foro de la ciudad ${ }^{58}$, que representa una figura alegórica en el octógono central, con las cuatro estaciones en las esquinas en forma de figuras alegóricas de erotes, así como animales y cestos estacionales encerrados en diferentes espacios geométricos: dátiles (invierno), uvas (otoño), espigas (verano) y flores (primavera).

58 G. López Monteagudo, op. cit. en nota 18, pp. 112-114; U. López Ruiz, «Hallazgo de un mosaico de temática estacional en Astigi (Écija, Sevilla), SPAL 14, 2005, pp. 301-313. Taboada Villanueva, B.: «Proceso de extracción de un mosaico de tema estacional sito en Avda. Miquel de Cervantes, 35 (Écija)», Astigi Vetus 2, 2006, pp. 149-154. 


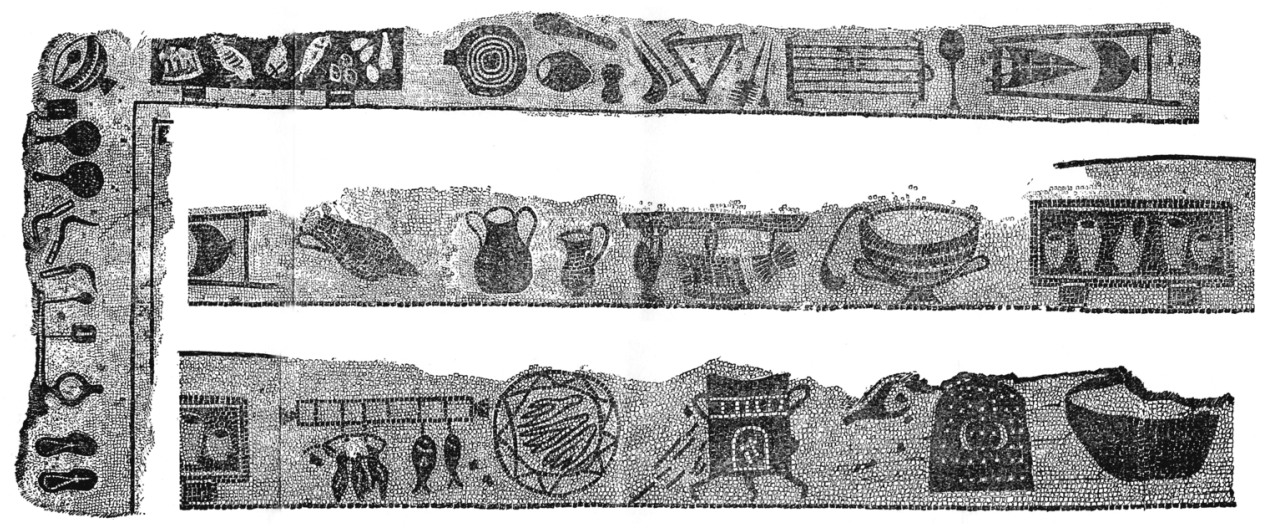

Fig. 16. Mosaico de la villa de Marbella. Finales del siglo I- comienzos del II.

\section{XENIA ASOCIADAS AL TEMA DE LOL MESES DEL AÑO}

Estas representaciones se documentan en el mosaico del corredor meridional del peristilo, de la villa Fortunatus de Fraga, Huesca, fechado a mediados del siglo IV ${ }^{59}$. En el cuadrado del mes de febrero aparece un ramo de granado con tres frutos; en marzo un ramo de vid; en mayo mijo; en junio ramo de vid y calabaza; en julio varias moras; en agosto frambuesas; en septiembre alcachofa o cardo, en noviembre madroño, en diciembre olivo.

\section{XENIA RELACIONADAS CON UNA DIVINIDAD}

Aparece en dos mosaicos, con diferente divinidad. En el citado pavimento de Torre de Palma, Monforte (supra). Y en el mosaico, unicum en todo el Imperio, de la villa de Bobadilla (Málaga), de la primera mitad del siglo $1{ }^{60}{ }^{60}$. En el emblema figura Príapo rodeado de flores, dos aves y un par de sandalias, mientras que en su corto chitón porta frutos a base de manchas de colores sin perfiles ni detalles, todo el conjunto formaría un jardín ${ }^{61}$. La imagen de Príapo fue muy representada en pintura y, sobre todo, en escultura ${ }^{62}$, algunas llevan el chitón levantado lleno de flores

59 D. Fernández-Galiano, op. cit. en nota 9, pp. 73-85, n. ${ }^{\circ} 120$, láms. XXXIV y XXXV. Para los atributos de los meses vid. H. Stern, «Les Calendriers romains illustrés», ANRWII,12,2, 1981, pp. 431-475.

60 P. Rodríguez Oliva, Mosaicos romanos de Bobadilla (Málaga), Málaga 1987, pp. 39-79; Idem, «Los mosaicos de la villa romana de La Bobadilla (Málaga)», BSAA LIV, 1988, pp. 137-ss.; G. López Monteagudo et alii, «Recientes hallazgos de mosaicos figurados en Hispania», VIlème. Colloque Internacional pour létude de Mosaïque Antique, Túnez 1999, pp. 520- 522, lám. CLXXV,1.

61 M.P. San Nicolás Pedraz, «Los espacios ajardinados en la musivaria romana», Espacio, Tiempo y Forma II/10, 1997, 163-165, fig. 26. J.M. Blázquez Marínez «Los jardines en la Hispania romana», Historia de los parques y jardines en España, Madrid 2001, pp. 21ss.

62 H. Herter, De Príapo, Giessen 1932, pp. 105-ss. 
y frutos como la escultura del Museo de Sousse ${ }^{63}$ o las halladas en el área malagueña, semejante a la imagen príapica del mosaico hispano.

A través del análisis de estos ejemplares se aprecia que el tema de xenia aparecen en los mosaicos hispanos decorando fundamentalmente las salas nobles de las villae y de las domus urbanas (triclinium, oecus...) respondiendo a la ideología de los domini de honrar su hospitalidad al tiempo que exaltaban los productos del mar y de la tierra como pequeñas obras de arte.

Los artistas locales hispanos siguen la tradición helenística (recordemos que derivan directamente de los modelos pictóricos) de encerrar los diferentes motivos de xenia en pequeños paneles o registros. Pero también los presentan aislados en una composición geométrica, vegetal o libre, peculiaridades propias del arte romano, como se aprecia también en el Norte de África u otras regiones del Imperio.

A veces las xenia tienen carácter estacional utilizándose como alegorías de las estaciones, frutos estacionales asociadas a las mismas o meses del año. En otros ejemplares están asociadas a figuras mitológicas, ya sean de tema marino o báquico. Por último queremos resaltar el pavimento de Marbella representando un bodegón con varios alimentos y objetos de cocina, unicum en la musivaria romana.

\section{CATALOGO}

1. CÓRDOBA (Plaza de la Corredera). Fragmento de un mosaico polícromo. En la moldura del pavimento muy deteriorado aparecen una guirnalda de laurel con alcachofas y otros frutos no identificables. Siglo II-III. J.M. BLÁZQUEZ (1981), p. 18, n. ${ }^{\circ}$, fig. 1, lám. 82A.

2. PISÒES (BEJA, PORTUGAL). Mosaico polícromo de esquema a compás, hallado en la habitación 9 de la villa considerada como de tipo cultual. En la guirnalda central aparecen cítricos, y estaciones a modo de xenia en las lunetas: aves dentro de un círculo, aves enfrentadas a un cántaro, aves picoteando un racimo de uvas, un cesto de flores. M.L. COSTA (1985), pp. 95-135; M.J. DURAN (1998), pp. 445-454; M. PESSOA (2005), pp. 1042-1043, fig. 6.

3. VEGA BAJA (TOLEDO). Mosaico polícromo hallado en el triclinium de la villa romana. Denominado el de los Peces por el tema representado en su emblema central. En la guirnalda de laurel que bordea dicho emblema aparecen cuatro grupos de vegetales y frutos, como uvas, espigas, flores y otras frutas, entre las que se distinguen manzanas y cítricos. Igualmente aparecen varias xenia en las esquinas junto a las estaciones y en diversos espacios cuadrangulares y en las lunetas del mosaico, con la particularidad de que coinciden con los grupos de xenia de las guirnaldas. Principios del siglo Iv. Museo Arqueológico de Santa Cruz de Toledo. J.M. BLÁZQUEZ (1982), pp. 36- 40, n. 26, láms. 20-23, 47-48.

63 L. Foucher, «Priape ithyphallique», Karthage 7, 1956, pp. 171-174, p. 174, fig. 1; H. Blank, «ll Maripara. Eine Priapstatue in Formella», RM 86, 1979, pp. 339- 360. 
4. MÉRIDA (calle Masona). Mosaico polícromo de los Aurigas, con un medallón enmarcado por una guirnalda de hojas de laurel con flores y frutas, de las cuales se aprecian manzanas. Segunda mitad del siglo Iv. A. BLANCO (1978a), n. ${ }^{\circ} 43$, pp. 45-46, láms. 76-79.

5. ARRÓNIZ (NAVARRA). Mosaico polícromo hallado en una habitación octogonal de la villa romana. Tiene una composición radiada irregular, con nueve radios alrededor de un círculo y en un octógono, determinando siete pentágonos y dos trapecios con un lado cóncavo en trenza. En cada uno de los nueve compartimentos se ha representado como fondo de paisaje una villa y en un primer plano un grupo integrado por un filosofo y una musa, como alusión a la cultura. En la guirnalda, muy deteriorada, que rodea el medallón central aparecen berengenas y otros frutos no identificados. Finales del siglo III o comienzos del IV d.C. Museo Arqueológico Nacional. J.M. BLÁZQUEZ y M.A. MEZQUIRIZ (1985), pp.15-22, n. ${ }^{\circ}$ 2, láms 50; M.A. MEZQUIRIZ (2003), pp. 220- 227.

6. SOTO DE RAMALETE (NAVARRA). Mosaico policromo de la habitación 5 de la villa. En el emblema, de forma cuadrada, aparece una guirnalda con frutos no identificados encerrando una cratera sostenida por dos putti; en los ángulos del mismo cestos de frutos como alegoris de las estaciones. Museo Arqueológico de Navarra. Siglo IV. J.M. BLÁZQUEZ y M.A. MEZQUIRIZ (1985), pp. 69- 73, n. ${ }^{\circ} 45$, fig. 11, láms. 41-42; D. FERNÁNDEZ-GALIANO (1987), n. ${ }^{\circ}$ 178, pp.110-11 láms. L-LI.

7. ITÁLICA. Mosaico polícromo de los Pájaros. En el emblema, de forma rectangular, aparece una guirnalda con frutos no identificados encerrando un motivo hoy desaparecido. En el resto del pavimento aparecen diferentes aves encerradas en cuadrados. Siglo II. In situ. A. PARLADE (1934), pp. 11 y 18, lám. XV; R. THOUVENOT (1940), pp. 649- 650, fig. 170; J.M. ALVAREZ MARTINEZ (1990), pp.; M. DURAN (1993), pp. 51-54, lám. III,5; I.J. JESNICK (1997), n. 34a, pp. 134135.

8. QUINTOS (PORTUGAL). Fragmento de mosaico policromo. Hoja de laurel que decoraba un cuadrado con un pez. Museo de Béja. R. SERPA PINTO, Inventario, pp. 176-177, lám. V, 8; Museo Regional de Beja. Catálogo de algunas das principias peças, Beja, s.d., p. 10, núm. 16, con dibujo de reconstrucción del pavimento.

9. TORRE DE PALMA, MONFORTE (PORTUGAL). Mosaico polícromo hallado en el triclinium de la villa romana. Se representa una guirnalda con peras y racimo de uvas bordeando el emblema cor restos de una figura recostada $\mathrm{M}$. HELENO (1962), pp. 333-334, EST. G.

10. CORNELLÀ DE LLOBREGAT (BARCELONA). Mosaico polícromo de la villa. Fue localizado en el ámbito de la planta de una basílica y de una zona de enterramiento de la misma época. Fragmento con decoración geométrica y floral a base de hojas en forma de guirnalda y un ramo con una granada. Siglo IV-V. X. BARRAL (1978), pp. 122- 124, láms. LXXIX y LXXX,1; J.M. SOLIAS (1990), pp. 1277-1278, fig. 675; J. BONAMUSA ROURA (2003), pp. 8-9, lám. 1. 
11. ARRONIZ (NAVARRA). Mosaico polícromo hallado en el escalón que da paso a la zona absidiada del oecus de la villa. Se representa una guirnalda con frutos, flores, pájaros, así como varios animales (tigre, caballo, pántera y león). Siglo IV. M.A. MEZQUIRIZ (2003), pp. 231-235.

12. COLONIA AUGUSTA FIRMA ASTIGI (ÉCIJA). Mosaico polícromo. Localizado en la calle Miguel de Cervantes, cerca del foro, en la zona Sur del cardo maximus. En el campo musivo figuraría cuatro cuadrados, y alrededor de cada uno de ellos, una composición geométrica a base de esvásticas enlazadas, formando dobles meandros compuestos, en blanco y negros, con nudos de Salomón aislados en cada esquina de los cuadrados. En uno de los espacios cuadrados se conserva un ramo de granada con frutos alternando los colores rojos y verdes con los blancos y negros; del cuadrado anejo aparecen dos hojas de la base del tallo de otro ramo de frutos; el espacio simétricamente opuesto existe solo restos del cuadrado, mientras que del cuarto nada se conserva. Museo de Ecija. Siglo II-III F. FERNÁNDEZ GOMEZ (1998), pp. 32-41. G. LÓPEZ MONTEAGUDO (2006), p. 121, fig. 5.

13. VILLARES, QUINTANA DEL MARCO (LEÓN). Mosaico policromo. En un cuadrado se representa un faisán mirando hacia la izquierda. Se conserva en el Museo Arqueológico Nacional. Siglo Iv. J.M. BLÁZQUEZ et alii (1989b), pp. 48-49, láms. 27 y 47; VVAA (2001), p. 46.

14. MÉRIDA. Mosaico policromo hallado en el interior de la Casa de la Huerta de Otero. Lleva a cada lado de una banda de meandros con espacios cuadrados un pez o un molusco. In situ. Finales del siglo II o comienzos del III. A. BLANCO (1978a), p. 49, n. ${ }^{\circ}$ 56, lám. 87.

15. MÉRIDA. Mosaico policromo, muy fragmentado, localizado en una domus de Mérida, en la actual calle de Suárez Somonte, cerca del Teatro y Anfiteatro. Se aprecia parte de la orla exterior con la representación de murallas, en el emblema aparece una perdiz encerrada en un cuadrado. G. MÉNDEZ GRANDE (2004), p. 264, láms. 3-4.

16. SANTA VITÓRIA DO AMEIXIL (ESTREMOZ, ALTO ALEMTEJO, PORTUGAL). Mosaico policromo de la sala E de esta villa urbana. Presenta peces dentro de cuadrados, de los que se han identificado delfines, calamares y anguila. Siglo IV. L. CHAVES (1938), pp. 14-117, est. IV, fig. 16.

17. VEGA DEL CIEGO (ASTURIAS). Mosaico policromo. Composición a base de cuadrados con peces, palomas afrontadas, crateras y otros motivos geométricos. Comienzos del siglo v J.M. BLÁZQUEZ et alii (1993), pp. 51-53, n. 32, láms. 17-20.

18. BASILICA DE SANTA MARÍA (TARRASA). Mosaico policromo con delfines en los rectángulos. Segunda mitad del siglo v. X. BARRAL I ALTET (1978), n. ${ }^{\circ}$ 144, lám. XC.

19. CÓRDOBA (Avenida de la Victoria). Mosaico polícromo. En una composición octogonal de cruces que generan un meandro de cuadrados a ambos lados 
se representa un ramo de cuatro granadas en el interior de un círculo enmarcado en su interior por un filete denticulado. Museo Arqueológico de Córdoba. Finales del siglo II- comienzos del III. A. MARCOS POUS y A.M. VICENT ZARAGOZA (1985), p. 240; M. MORENO GONZALEZ (1995), pp. 47- 49, lám. 11.

20. MÉRIDA. Mosaico policromo del corredor de la Casa del Anfiteatro. Ocupando toda la superficie del pavimento aparecen peces encerrados en círculos, de los que se han identificado: delfín, merluza, lenguado, congrio, murena y mero. In situ. Siglo III. A. BLANCO (1978a), p. 42, n. ${ }^{\circ}$ 31, láms. 57-62.

21. ARTIEDA DE ARAGÓN (ZARAGOZA). Mosaico policromo de una de las habitaciones de la villa dispuestas a un peristilo. Tiene una composición de octógonos adyacentes con una estrella formada por dos cuadrados, formando espacios cuadrados y romboidales. En el interior de las estrella existe un círculos que contienen peces, aves y cestos de flores. En el emblema cuadrado aparece una fuente Finales del siglo IV o comienzos del V. D. FERNÁNDEZ-GALIANO (1987), pp. 29-31, n. ${ }^{20}$, láms. XI-XII. M.P. SAN NICOLÁS PEDRAZ, PEDRAZ, M. (1997), p. 151 , fig. 12.

22. MÉRIDA. Mosaico policromo de la Caza del jabalí con perros que ocupa el emblema central, rodeando a éste figuran peces, flores, cráteras y diversos motivos geométricos. Principios del V. J.M ALVAREZ MARTíNEZ, 1990, pp. 60-65, fig. 4, láms. 27-29.

23. CAMPO DE VILLAVIDEL (LEÓN). Mosaico policromo de Cacería de la sala N. de la villa. Presenta una composición de octógonos alternando con hexágonos, rombos y cuadrados. En los hexágonos aparecen peces, mientras que en las otros espacios diferentes figuras geométricas. En el emblema cuadrado se representa una escena de cacería. Siglo IV. J.M. BLÁZQUEZ et alii (1993), pp. 21-23, n. ${ }^{\circ}$, láms. 4-5,24-25.

24. MÉRIDA (calle de Sagasta). Mosaico policromo, muy deteriorado, de Opora, localizado las excavaciones de urgencia del 2002, en una domus cerca de la muralla, posiblemente pertenezca un oecus o tablinum. En la cenefa del pavimento con motivos geométricos, hojas de pelta y cables simples aparece, encerrado en un octógono, un cesto con indeterminadas frutas rodeado de guirnaldas. En el emblema aparece varios animales: bóvidos y équidos y vegetación de palmeras y diversas plantas, así como restos de una figura que se ha interpretado como la representación alegórica de Opora, como indicaría la inscripción conservada. Finales del siglos III-IV. P.D. SANCHEZ BARRERO (2005), p. 445, fig. 6; G. LÓPEZ MONTEAGUDO (2005-2006), pp. 347-364.

25. MATERNO, CARRANQUE (TOLEDO). Mosaico polícromo de la antesala del oecus de la villa. Es de forma rectángular, con una composición ortogonal de cables de dos cabos, formada por cinco octógonos irregulares, uno central y cuatro laterales, unidos entre sí por cuatro cruces adyacentes de brazos iguales que determinan hexágonos y cuadrados irregulares, originándose trapecios y triángulos en el centro y en las esquinas; en los espacios octogonales figuran cestos con frutas, posiblemente cítricos, algunos con dos flores (rosas) flanqueando el cesto, 
además de cráteras con pie y peces, estos últimos en los hexágonos. In situ. Siglo IV. D. FERNÁNDEZ-GALIANO (1991), pp. 29-30.

26. PEDRAS D'EL REI (TAVIRA, PORTUGAL). Varios fragmentos de un mosaico policromo con peces dentro de octógonos. Sin datación. Mosaicos ...(2005), pp. 32-33.

27. SAN MARTÍN DE LOSA (BURGOS). Mosaico polícromo de la habitación $\mathrm{C}$, de la villa. El pavimento, de forma cuadrada, presenta una composición ortogonal de octógonos adyacentes enlazados entre sí por una red de esvásticas compuestas por cenefas de damero, esquema compositivo denominado por Salies «Oktogonssystem III» Los octógonos encierran en su interior tallos de vid, coronas de laurel, racimos de uvas como en los mosaicos de las villas de la Vega Baja y de Torre de Palma supra, así como aves, peces, delfines y monstruos marinos Finales del siglo IV- comienzos del V. G. LÓPEZ MONTEAGUDO et alii (1998), pp. 3032, n. ${ }^{\circ} 14$, fig. 7, láms. 15-18.

28. MÉRIDA. Fragmento del Mosaico de la Medusa. Casa de la Huerta de Otero. Presenta cuadrados con pájaros y máscaras, rectángulo con un pez y hexágonos con pavos, así como una cabeza de Medusa en el emblema octogonal central. In situ. Finales del siglo II o comienzos del III. A. BLANCO (1978a), n. ${ }^{\circ} 57$, láms. 88-90.

29. SISAPO-LA BIENVENIDA (ALMÓDOVAR DEL CAMPO, CIUDAD REAL). Mosaico policromo localizado en la habitación n. ${ }^{\circ} 20$ de la domus de las columnas rojas, oecus. Presenta una composición geométrica a base de rombos con diversos peces y pulpos o clamares, así como cuadrados con máscaras y crateras. Siglo II-III. In situ. C. GUIRAL PELEGRÍN y M. ZARZALEJOS PRIETO (Nov./déc. 2006), pp. 40 y 46;C. GUIRAL PELEGRÍN y M. ZARZALEJOS PRIETO (2006), p. 140, fig. 9.

30. EL EJIDO (ALMERÍA). Mosaico policromo de composición geométrica, en donde aparecen aves en los círculos, zarcillos de vid en los triángulos, así como otros motivos figurados (pantera, fauno, sátiro, medusa, crateras, máscaras). Siglo III. G. LÓPEZ MONTEAGUDO, et alii (1999), p. 520, lám. CLXXIV.

31. SASAMÓN (BURGOS). Mosaico polícromo de la mansio Segisamo, en un lugar denominado Arquillo, fuera del núcleo urbano, con una composición geométrica. En el octógono central esta representado un personaje marino en busto y con dos pinzas de cangrejo en la cabeza, que se ha interpretado como un tritón, iconografía única en este tipo de representaciones. Los octógonos laterales van decorados con otros animales marinos: ciervos, caballo, grifo, pantera. En los hexágonos figuran peces y distintas clases de pájaros, mientras que en el resto de las figuras geométricas aparecen motivos florales, cruces griegas y nudos de Salomón. Finales del siglo II- comienzos del III. Se conserva en la Iglesia Parroquial de Sasamón. ABÁSOLO, J.A. y GARCíA, R. (1993), pp. 179- 192, fig. 95, láms. XIXXXVI; TORRES CARRO, M. (1990), pp. 110- 114; LÓPEZ MONTEAGUDO, G. et alii (1998), p. 32, n.․ 159, fig. 8, láms. 19-20 y 44. 
32. QUINTANILLA DE LA CUEZA (PALENCIA). Mosaico policromo de la habitación $X X$ de la villa. Composición geométrica con peces en los octógonos y hexágonos. Finales del siglo III- mediados del Iv. M.A. GARCÍA GUINEA, M.A. (2000), pp. 251-254, lám. 295.

33. CÓRDOBA. Mosaico policromo hallado en la sacristía de la basílica bizantina. Los octógonos están ocupados por parejas de delfines afrontados a un tridente y los círculos con otros símbolos cristianos, como aves, granadas, recipiente metálico lleno de agua y cesto con panes. Mediados del siglo vi. P MARFIL RUIZ (1996).

34. CÓRDOBA. Mosaico policromo de Thalassius, hallado en uno de los cubicula de una domus de Córdoba. En el emblema aparece una escena de caza del dominus Thalassius con sus perros, identificados todos con sus nombres. En la cenefa, que rodea el pavimento, de meandros, cuadrados y arcadas, figura en las arcadas situadas en la parte central de sus cuatro lados, un ave, identificándose la paloma, el pato y el pavo. Segunda mitad del siglo IV. F. MURILLO REDONDO y J.R. CARRILLO DIAZ-PINÉS (1999), pp. 535-537, láms. CLXXXIV.

35. EL ROMERAL, ALBESA, LÉRIDA. Mosaico polícromo del pasillo O. del peristilo de la villa. En una composición de arcadas o composición ortogonal de escamas adyacentes se encuentran alcachofas que en algunas conservan sus hojas y cestas con frutos sin identificar, además de otros motivos como aves sobre ramos, capullos con hojas, flores y tiestos agallonados con pies. Segunda mitad del siglo IV. J.M. BLÁZQUEZ et alii (1989a), p. 14-15, n. ${ }^{\circ}$ 2, láms 1,2 y 20.

36. SOTO DE RAMALETE, TUDELA (NAVARRA). Mosaico polícromo del oecus de la villa. La superficie del pavimento, de forma rectangular, ostenta una composición de dos guirnaldas enlazadas que dibujan semicírculos de dos tamaños diferentes sobre una base de cuadrados. En los espacios libres entre guirnaldas se representan ramos con sus hojas de flores y frutos como liláceas, campánulas, manzanas, peras y granadas. En la guirnalda inferior aparece un delfín nadando. Siglo IV. J.M. BLÁZQUEZ y M.A. MEZQUIRIZ (1985), pp. 61-63, n. ${ }^{\circ} 43$, fig. 9, lám. 55 (foto en portada); D. FERNÁNDEZ-GALIANO (1987), n. ${ }^{\circ}$ 179, p. 111, lám. LII; M. GUARDIA PONS (1992), pp. 101-106;

37. ITÁLICA (SEVILLA) Mosaico polícromo con escena de circo, conocido a través de un dibujo de A. Laborde y se ignoran las circunstancias de su hallazgo. El campo musivo que encuadra la representación circense está ocupada por treinta y seis medallones con los bustos de las Musas y otras figuras mitológicas, mientras que los motivos de xenia están dispersos, pudiendo identificarse: peras, un racimo de uvas y varias cidras. Finales del siglo III o principios del IV A. BLANCO (1978b), pp. 55-56, n. ${ }^{\circ}$ 43, láms. 61-73 y 75; J. POLZER (1963), pp. 119 ss.; J.H. HUMPHREY (1986), pp. 233ss; G. LÓPEZ MONTEAGUDO (1994), pp. 348-34.

38. FRAGA (HUESCA). Mosaico polícromo de Fortunatus que pavimentaba una habitación de prestigio de la villa. Se representan varios motivos de xenia dispersos (aves, guirnaldas, erotes, flores, frutos...) en un panel, rectangular enmar- 
cado por una banda de ajedrezado cortada por el nombre del propietario Fortunatus, dividido en medio por un crismón con la alfa y la omega; todo el mosaico esta rodeado por un roleo vegetal. Figura un ramo compuesto por dos hojas lanceoladas y una fruta de color pardo-amarillento que ha sido identificada con un melocotón; ave y frente a ella un ramo de olivas, crátera con racimos de uvas entre otros elementos; ave picoteando los frutos de un cesto; racismo de vid entre otros motivos; racimo de vid, racimo de uvas y restos de un matorral. D. FERNÁNDEZGALIANO (1987), pp.86-88, n. 122, láms. XXXVII-XXXVIII,1.

39. VILLARES, QUINTANA DEL MARCO (LEÓN). Mosaico polícromo. Se representa aisladamente tres perdices. Se conserva en el Museo Arqueológico Nacional. Siglo IV. J.M. BLÁZQUEZ et alii (1989b), pp. 48-49, láms. 27 y 47; VVAA (2001), p. 48.

40. MARBELLA (MÁLAGA). Mosaico en blanco y negro probablemente de un patio porticado de la villa. Se representa en frisos lineales, que bordearían el esquema central, un bodegón con alimentos y objetos de cocina. Entre la variada exposición figura un manojo de legumbres, espárragos y una fuente con puerros o calabacines, junto a otros productos del campo y del mar, como perdices y peces. Finales del siglo I o comienzos del II. C. POSAC MON, (1963); C. POSAC MON 1972, pp. 98, 100, lám. II,2; J.M. BLÁZQUEZ (1981), pp. 81-83, n. ${ }^{\circ}$ 55, fig. 22-23, láms 62-66; A. BALIL ILLANA, (1983), pp. 161-174.

41. COMUNIÓN (ÁLAVA). Mosaico de Diana polícromo de una habitación cuadrada y con ábside de la villa. Estrella de dos cuadrados irregular inscrita enlazada en un cuadrado, determinando cuadriláteros irregulares en los ángulos y triángulos laterales en trenza. En el centro figura la diosa Diana y en los ángulos tres cestos de frutas, manzanas, peras y cerezas, y un cuadrado con una cruz central. Mediados del siglo III o segunda mitad del IV. M. TORRES (1981), pp. 321-327, fig. 5; D. FERNÁNDEZ-GALIANO (1987), pp.133-134, n. 206, lám. LXXV

42. COLONIA AUGUSTA FIRMA ASTIGI (ÉCIJA) Mosaico policromo localizado cerca del foro de la ciudad, en la calle Miguel de Cervantes 35. Representa una figura alegórica en un octógono central con las cuatro estaciones en las esquinas así como animales y cestos estacionales: dátiles (invierno), uvas (otoño), espigas (verano) y flores (primavera). El esquema compositivo se encuadra en el «Kreissystem VII. Zentralkomposition», Siglo II-III. U. LÓPEZ RUIZ (2005), pp. 301-313; G. LÓPEZ MONTEAGUDO (2006) 112-114; B. TABOADA VILLANUEVA (2006), pp. 149-154.

43. FRAGA (HUESCA). Mosaico policromo del corredor meridional del peristilo de la villa. Aparecen encerrados en cuadrados diversas representaciones alegóricas de los meses. Mediados del siglo Iv. FERNÁNDEZ-GALIANO; D.(1987), pp. 73-85, n. ํ 120, láms. XXXIV y XXXV.

44. BOBADILLA (MÁLAGA). Mosaico policromo, en el emblema figura Príapo rodeado de flores, dos aves y un par de sandalias, mientras que en su corto chitón porta frutos a base de manchas de colores sin perfiles ni detalles. Primera mitad 
del siglo III. P. RODRIGUEZ OLIVA (1987), pp. 39-79; P. RODRIGUEZ OLIVA (1988), pp. 137-ss.; G. LÓPEZ MONTEAGUDO et alii (1999), pp. 520- 522, lám. CLXXV,1; M.P. SAN NICOLÁS PEDRAZ (1997) 163-165, fig. 26; J.M. BLÁZQUEZ (2001), pp. 21-35.

\section{BIBLIOGRAFÍA DEL CATÁLOGO}

ÁLVAREZ MARTíNEZ, J.M. (1990): «La iconografía de Orfeo en los mosaicos hispanorromanos", Estudios sobre iconografía. Actas del Homenaje a Alberto Balil, Guadalajara, pp. 29-59.

BALIL ILLANA, A. (1961): «Arte helenístico en el levante español», Archivo Español de Arqueología XXXI, pp. 41-52.

BALIL ILLANA, A. (1983): «Un bodegón en mosaico hallado en Marbella (Málaga)», Baetica 6, pp. 161-174.

BARRAL, X. (1978): Les mosaïques romaines et mediévales de la Regio Laietana, BarceIona.

BLANCO, A. (1978a): Mosaicos romanos de Mérida, CMRE I, Madrid.

BLANCO, A. (1978b): Mosaicos romanos de Italica, CMRE II, Madrid.

BLÁZQUEZ, J.M.(1981): Mosaicos romanos de Córdoba, Jaén y Málaga, CMRE III, Madrid.

BLÁZQUEZ MARTíNEZ, J.M.: «Los jardines en la Hispania romana», Historia de los parques y jardines en España, Madrid 2001, pp. 21-35.

BLÁZQUEZ, J.M. y MEZQUIRIZ, M.A. (1985): Mosaicos romanos de Navarra, CMRE VII, Madrid.

BLÁZQUEZ, J.M. et alii (1989a): Mosaicos romanos de Lérida y Albacete, CMRE VIII, Madrid.

BLÁZQUEZ, J.M. et alii (1989b): Mosaicos romanos del Museo Arqueológico Nacional, CMRE IX, Madrid.

BLÁZQUEZ J.M. et alii (1993): Mosaicos romanos de León y Asturias, CMRE X, Madrid.

BONAMUSA ROURA, J. (2003): Los mosaicos de la Layetania romana, Curso de Doctorado de la UNED, Madrid.

COSTA, M.L. (1985): «Contribuiçâo para o estudo de alguns dos mosaicos da villa romana de Pisôes", Arquivo de Beja II, serie 2. ${ }^{\text {a }}$, pp. 95-135.

CHAVES, L. (1938): «A villa de Santa Vitória do Ameixial. Excavaçôes em 1915-1916», O Arqueologo Portugués 30, pp. 14-117.

DARMON, J.P. et alii (2001): Trames géométriques végétalisees. Collection de l'école française de Rome 288. Roma.

DURAN, M.J. (1993): Iconografía de los Mosaicos Romanos en la Hispania Imperial, Barcelona.

DURAN, M.J. (1998): «Algunas consideraçoes sobre a iconografia das estaçoes do ano: a villa romana de Pisoes», Homenaxe a Ramón Lorenzo, Vigo, pp. 445-454.

FERNÁNDEZ-GALIANO, D. (1987): Mosaicos del Convento Cesaraugustano, Zaragoza.

FERNÁNDEZ-GALIANO, D. (1991) «La villa de Materno, Carranque, Toledo». Revista de Arqueología 127, pp. 29-30.

FERNÁNDEZ-GALIANO, D. (1994): «The villa of Maternus at Carranque Fifth International Colloquium on ancient mosaics (Bath, England 1987)», Ann Arbor, pp. 199- 210.

FERNÁNDEZ GOMEZ, F. (1998): «Un conjunto musivario excepcional en Ecija», Revista de Arqueología XIX, pp. 32-41.

GARCÍA GUINEA, M.A. (2000): La villa romana de Quintanilla de la Cueza (Palencia). Memoria de las excavaciones 1970-1981, Salamanca.

GUARDIA PONS, M. (1992): Los mosaicos de la antigüedad tardía en Hispania. Estudios de iconografía, Barcelona. 
C. GUIRAL PELEGRÍN y M. ZARZALEJOS PRIETO, «Les peintures romaines dans la capitale du cinebre hispanique», Dossier d Archéologique 318, Nov./déc. 2006, pp. 40-46.

GUIRAL PELEGRÍN, C. y ZARZALEJOS PRIETO, M. (2006): «La decoración pictórica de la domus de las columnas rojas de Sisapo-La Bienvenida (Almodóvar del Campo, Ciudad Real)», en J.M. Maillo y E. Baquedano (eds.), Miscelánea en Homenaje a Victoria Cabrera. Zona Arqueológica 7, vol. II, pp. 135-147.

HELENO, M. (1962): «A vill lusitan-romana de Torre de Palma (Monforte)», O Arqueólogo portugués IV, pp. 333-340

HUMPHREY, J.H. (1986): Roman Circuses, Londres.

JESNICK, I.J. (1997): The image of Orpheus in roman mosaic. An exploration of the figure of Orpheus in Greco-Roman art and culture with special reference to its expresion in the medium of mosaic in late Antiquity, BAR International Series, 671, Oxford.

LÓPEZ MONTEAGUDO, G. (1994): «Mosaicos romanos de circo y anfiteatro», VI Coloquio Internacional sobre Mosaico Antiguo (Palencia-Mérida 1990), Guadalajara.

LÓPEZ MONTEAGUDO, G. (2006) «Las casas de los extranjeros en la colonia Augusta Firma Astigi', L'Africa Romana XVI (Rabat 2004), pp. 107-132.

LÓPEZ MONTEAGUDO, G. et alii (1998): Mosaicos romanos de Burgos CMRE XII, Madrid.

LÓPEZ MONTEAGUDO G. et alii, (1999): «Recientes hallazgos de mosaicos figurados en Hispania», VIlème. Colloque Internacional pour létude de Mosaïque Antique, Túnez, pp. 520- 522.

LÓPEZ MONTEAGUDO, G. (2005-2006): Un nuevo mosaico de Augusta Emerita con la representación alegórica de Opora», Assaph 10-11, pp. 347-364.

LÓPEZ RUIZ, U. (2005): «Hallazgo de un mosaico de temática estacional en Astigi (Écija, Sevilla), SPAL 14, pp. 301-313.

MARCOS POUS, A. y VICENT ZARAGOZA, A.M. (1985): «Investigación, técnicas y problemas de las excavaciones en solares de la ciudad de Córdoba y algunos resultados topográficos generales», Arqueología de las ciudades modernas superpuestas a las antiguas, Zaragoza.

MARFIL RUIZ, P. (1996): La iglesia de Santa Catalina del antiguo convento de Santa Clara (Córdoba). Aspectos Arqueológicos, Patrimonio y ciudad. Jornadas Europeas de Patrimonio 1996, Córdoba.

MÉNDEZ GRANDE, G. (2004): «Restos de una domus con pavimento musivo y su posterior evolución. Intervención arqueológica realizada en el solar n. ${ }^{\circ} 83$ de la c/ Suárez Somonte», Memoria 7, pp. 257-267.

MORENO GONZALEZ, M. (1995): Aproximación al estudio de la decoración musivaria en Colonia Patricia Corduba, Memoria de Licenciatura, Univ. de Córdoba, Córdoba.

MEZQUIRIZ, M.A. (2003) La villa romana de Arellano, Pamplona.

Mosaicos romanos na Coleçcôes do Museo Nacional de Arqueologia, Lisboa 2005.

MURILLO REDONDO, F. y CARRILLO DIAZ-PINÉS, J.R. (1999): «El mosaico de Thalassius en Corduba», La Mosaïque Gréco-Romaine VII, t. 2, Túnez 1999, pp. 535-537.

PARLADE, A. (1934): «Excavaciones en Itálica. Campañas 1925-1932 ».. Memorias de la Junta Superior del Tesoro Artístico 127.

PESSOA, M. (2005): «Renouveau artistique des mosaïques romaines représentant les saisons au Portugal», La Mosaïque Gréco-romaine IX,2, Roma, pp. 1042-1043.

POLZER,J. (1963): Circus Pavements, Nueva York.

POSAC MON, C. (1963): El mosaico romano de Marbella, Málaga.

POSAC MON, C. (1972): «La villa romana de Marbella», Noticiario Arqueológico Hispano I, pp. 98-100.

RODRIGUEZ OLIVA, P. (1987): Mosaicos romanos de Bobadilla (Málaga), Málaga.

RODRIGUEZ OLIVA, P. (1988): «Los mosaicos de la villa romana de La Bobadilla (Málaga)», BSAA LIV, pp. 137-145.

SANCHEZ BARRERO, P.D. (2005): «Trabajo desarrollado por el Equipo de Seguimiento de Obras durante el año 2002», Mérida. Excavaciones Arqueológicas 8, 2005, pp. 431-446. 
SAN NICOLÁS PEDRAZ, M.P (1997): «Los espacios ajardinados en la musivaria romana», Espacio, Tiempo y Forma, UNED, Serie II (Historia Antigua), vol- 10, pp. 137-175.

SOLIAS, J.M.. (1990): El poblament ibérico-romà del curs inferior del Llobregat (Tesis Doctorales de la Universitat de Barcelona), Barcelona.

TABOADA VILLANUEVA, B. (2006): «Porceso de extracción de un mosaico de tema estacional sito en Avda. Miquel de Cervantes, 35 Ëcija)», Astigi Vetus 2, pp. 149-154.

THOUVENOT, R. (1940): Essay sur la province Bétique, Paris.

TORRES, M. (1981): «Los mosaicos descubiertos en el siglo XVIII en la villa de Cabriaza (Alava)», Estudios de Arqueología Alavesa 10, pp. 321-327.

VV.AA. (2001): Mosaico Romano del Mediterráneo, Madrid. 